\title{
A New Look at Oligopoly: Implicit Collusion Through Portfolio Diversification*
}

\author{
José Azar ${ }^{\dagger}$ \\ Princeton University
}

November 8, 2011

Job MARKet PAPER

\begin{abstract}
In this paper, I develop a model of oligopoly with shareholder voting. Instead of assuming that firms maximize profits, the objective of the firms is decided by majority voting. This implies that portfolio diversification generates tacit collusion. In the limit, when all shareholders are completely diversified, the firms act as if they were owned by a single monopolist. In a model of general equilibrium oligopoly with shareholder voting, higher levels of wealth inequality and/or foreign ownership lead to higher markups and less efficiency. The empirical section of the paper studies the network of common ownership of publicly traded US corporations generated by institutional investors. I show that the density of the network more than tripled between 2000 and 2010. I explore the empirical relation between markups and networks of common ownership. The evidence is consistent with the hypothesis that common ownership acts as a partial form of integration between firms.
\end{abstract}

${ }^{*}$ I thank my advisor, Chris Sims, for invaluable feedback. I am also grateful to Dilip Abreu, Avidit Acharya, Roland Benabou, Harrison Hong, Oleg Itskhoki, Jean-François Kagy, Scott Kostyshak, Stephen Morris, Juan Ortner, Kristopher Ramsay, Jose Scheinkman, Hyun Shin, David Sraer, Wei Xiong, and seminar participants at Princeton University for helpful comments. This work was partially supported by the Center for Science of Information (CSoI), an NSF Science and Technology Center, under grant agreement CCF0939370.

${ }^{\dagger}$ Address: Department of Economics, 001 Fisher Hall, Princeton, NJ 08544. Email: jazar@princeton. edu. 


\section{Introduction}

What is the effect of ownership structure on market structure? Models of oligopoly generally abstract from financial structure by assuming that each firm in an industry is owned by a separate agent, whose objective is to maximize the profits of the firm. In these models, any given firm is in direct competition with all the other firms in the industry. In practice, however, ownership of publicly traded companies is dispersed among many shareholders. The shareholders of a firm, in turn, usually hold diversified portfolios, which often contain shares in most of the large players in an industry. This diversification is, of course, what portfolio theory recommends that fund managers should do in order to reduce their exposure to risk. The increasing importance in equity markets of institutional investors, which tend to hold more diversified portfolios than individual households, suggests that diversification has increased through the second half of the twentieth century and the beginning of the twentyfirst. Figure 1 shows that the fraction of U.S. corporate equities owned by institutional investors increased from less than 10 percent in the early 1950s to more than 60 percent in $2010 .^{1}$

This paper studies the implications of portfolio diversification for equilibrium outcomes in oligopolistic industries, both from a theoretical and an empirical point of view. The first contribution of the paper is to develop a partial equilibrium model of oligopoly with shareholder voting. Instead of assuming that firms maximize profits, I model the objective of the firms as determined by the outcome of majority voting by their shareholders. When shareholders vote on the policies of one company, they take into account the effects of those policies not just on that particular company's profits, but also on the profits of the other companies that they hold stakes in. That is, because the shareholders are the residual claimants in several firms, they internalize the pecuniary externalities that each of these firms generates on the others that they own. This leads to a very different world from the one in which firms compete with each other by maximizing their profits independently, as in classical Cournot or Bertrand models of oligopoly. In the classical models, the actions of each firm generate pecuniary externalities for the other firms, but these are not internalized because each firm is assumed to have a different owner.

By modeling shareholders as directly voting on the actions of the firms, and having managers care only about expected vote share, I abstract in this paper from the conflict of

\footnotetext{
${ }^{1}$ See also Gompers and Metrick (2001) and Gillan and Starks (2007).
} 
interest between owners and managers. In practice, shareholders usually do not have a tight control over the companies that they own. Institutional owners usually hold large blocks of equity, and the empirical evidence suggests that they play an active role in corporate governance. $^{2}$ The results of the paper should thus be interpreted as showing what the outcome is when shareholders control the managers. From a theoretical point of view, whether agency problems would prevent firms from internalizing externalities that they generate on other portfolio firms depends on the assumptions one makes about managerial preferences. This would only be the case, to some extent, if the utility of managers is higher when they do not internalize the externalities than when they do.

Hansen and Lott (1996) argued that, when shareholders are completely diversified, and there is no uncertainty, they agree unanimously on the objective of joint profit maximization. However, in practice shareholders are not completely diversified, and their portfolios are different from each other. Moreover, in reality company profits are highly uncertain, and shareholders are not risk neutral, which is also a potential cause for disagreement among shareholders. The model of oligopoly with shareholder voting developed in this paper allows for a characterization of the equilibrium in cases in which shareholders do not agree unanimously on any policy. This has several advantages. First, the model permits a characterization of the equilibrium outcome of an oligopolistic industry for any portfolio matrix. This is useful, for example, to compare the effects of portfolio diversification on the industry equilibrium under price and quantity competition. Second, the model makes it clear that complete diversification is not sufficient for shareholder unanimity. When profits are uncertain and shareholders are risk averse, they will in general not agree unanimously on the policies of the firms. However, the equilibrium can still be characterized as collusive in the sense that it is equivalent to the one a monopolist who maximized a weighted average of shareholder utilities would choose.

The second contribution of the paper is to introduce the oligopoly model with shareholder voting in a simple general equilibrium framework. In a general equilibrium context, firms also take into account the interests of their shareholders as consumers of the goods they produce, in addition to their interests as profit recipients. Thus, in equilibrium firms will engage in corporate social responsibility. The reason is that the owners of the oligopolistic firms, as members of society, internalize the externalities (pecuniary or otherwise) that the

\footnotetext{
${ }^{2}$ See, for example, Agrawal and Mandelker (1990), Bethel et al. (1998), Kaplan and Minton (1994), Kang and Shivdasani (1995), Bertrand and Mullainathan (2001), and Hartzell and Starks (2003).
} 
oligopolistic firms generate on society, at least to some extent. In practice, if wealth inequality is high, it may be a reasonable approximation to think that in most circumstances shareholders will consume a small proportion of the goods produced, and thus the fact that they are consumers as well as profit recipients will have a small effect on firm behavior, if it is not simply ignored altogether by managers.

It is interesting to note that, while the independent profit maximization assumption may be unrealistic from the point of view of partial equilibrium oligopoly, it is problematic at a more fundamental level from the point of view of general equilibrium oligopoly models. In these models, portfolios should be endogenous, and under reasonable assumptions agents will choose to diversify their ownership in the firms. In general equilibrium models with complete markets and perfect competition, the profit maximization assumption is justified for any ownership structure by the Fisher Separation Theorem. ${ }^{3}$ This theorem says that, in the case of perfect competition and complete markets, shareholders agree unanimously on the independent profit maximization objective. Under imperfect competition, however, the profit maximization assumption rests on much shakier microfoundations. Except for the unrealistic case of independently owned firms, the assumption that firms maximize profits independently is ad hoc.

A third contribution of the paper is to document the extent of common ownership induced by institutional investors for publicly traded corporations in the United States. I construct a network whose nodes are publicly traded U.S. corporations. Two companies are considered connected in the network if there is an institutional investor that owns at least $5 \%$ of each company. The density of this network more than tripled between 2000 and 2010, increasing from $4 \%$ to $14 \%$. I then construct a ranking of asset managers by the number of blockholdings, where a fund is considered to be a blockholder in a company if it owns at least $5 \%$. The percentage of companies in the sample having a top 5 fund as a blockholder has increased from around $30 \%$ of the companies in the sample to almost $50 \%$.

Finally, this paper explores the empirical relationship between markups and networks of common ownership. The main findings are the following. First, industries with a higher density of common ownership networks within the industry have higher markups. This is consistent with common ownership with other firms in the same industry acting as a form of partial horizontal integration. Second, industries whose firms have more common ownership

\footnotetext{
${ }^{3}$ See, for example, Jensen and Long (1972), Ekern and Wilson (1974), Radner (1974), Grossman and Stiglitz (1977), DeAngelo (1981), Milne (1981), and Makowski (1983).
} 
links with other firms outside the industry have lower markups. This is consistent with a vertical integration interpretation, with the associated reduction in double marginalization. Finally, using a panel vector autoregression (VAR) analysis, the timing suggests that causality goes from ownership structure to markups and not the other way around. A possible alternative interpretation could be that institutional investors have private information on the future evolution of markups. However, this alternative interpretation is at odds with the fact that shocks to common ownership with firms outside the industry have a negative effect on markups.

The results in this paper have potentially important implications for normative analysis. Economists generally consider portfolio diversification, alignment of interest between managers and owners, and competition to be three desirable objectives. In the model developed in this paper, it is not possible to fully attain all three. Competition and diversification could be attained if shareholders failed to appropriately incentivize the managers of the companies that they own. Competition and maximization of shareholder value are possible if shareholders are not well diversified. And diversification and maximization of shareholder value are fully attainable, but the result is collusive. This trilemma highlights that it is not possible to separate financial policy from competition policy.

The results of the paper also show that assessing the potential for market power in an industry by using concentration ratios or the Herfindahl index can be misleading if one does not, in addition, pay attention to the portfolios of the main shareholders of each firm in the industry. This applies to both horizontally and vertically related firms. In the model, diversification acts as a partial form of integration between firms. Antitrust policy usually focuses on mergers and acquisitions, which are all-or-nothing forms of integration. It may be beneficial to pay more attention to the partial integration that is achieved through portfolio diversification.

The endogenous corporate social responsibility that arises in the general equilibrium oligopoly model also has interesting normative implications. For example, foreign ownership would lead to less corporate social responsibility in the model, at least if foreigners consume lower amounts of local goods. This is consistent with the evidence presented in Blonigen and O'Fallon (2011), who show that foreign firms are less likely to donate to local charities. Also, to the extent that consumption of the oligopolistic goods increases less than proportionally with wealth, inequality generates lower levels of corporate social responsibility in equilibrium. Wealth inequality generates inefficiencies because it leads firms to use their market power to 
extract monopoly rents more aggressively.

This paper is organized as follows. Section 2 presents a review of the related literature. Section 3 lays out the basic model of oligopoly with shareholder voting. Section 4 shows results for the case of complete diversification. Section 5 applies the voting model to classic Cournot and Bertrand oligopoly, both in the case of homogeneous and heterogeneous goods. Section 6 embeds the voting model in a simple general equilibrium oligopoly framework. Section 7 presents empirical evidence on common ownership networks and markups. Section 8 concludes.

\section{Literature Review}

I rely extensively on insights and results from probabilistic voting theory. For a survey of this literature, see the first chapter of Coughlin (1992). I have also benefited from the exposition of this theory in Acemoglu (2009). These models have been widely used in political economy, but not, to my knowledge, in models of shareholder elections. I also use insights from the work on multiple simultaneous elections by Alesina and Rosenthal (1995), Alesina and Rosenthal (1996), Chari et al. (1997). Ahn and Oliveros (2010) have studied further under what conditions conditional sincerity is obtained as an outcome of strategic voting.

This paper is related to the literature on the intersection of corporate finance and industrial organization. The interaction between these two fields has received surprisingly little attention (see Cestone (1999) for a recent survey). The corporate finance literature, since the classic book by Berle and Means (1940), has focused mainly on the conflict of interest between shareholders and managers, rather than on the effects of ownership structure on product markets, while industrial organization research usually abstracts from issues of ownership to focus on strategic interactions in product markets. There are, however, important exceptions, such as the seminal contribution of Brander and Lewis (1986), who show that the use of leverage can affect the equilibrium in product markets by inducing oligopolistic firms to behave more aggressively. Fershtman and Judd (1987) study the principal-agent problem faced by owners of firms in Cournot and Bertrand oligopoly games. Poitevin (1989) extends the model of Brander and Lewis (1986) to the case where two firms borrow from the same bank. The bank has an incentive to make firms behave less aggressively in product markets, and can achieve a partially collusive outcome. In a footnote, Brander and Lewis (1986) mention that, although they do not study them in their paper, it would be interesting 
to consider the possibility that the rival firms are linked through interlocking directorships or through ownership by a common group of shareholders. From the point of view of industrial organization, Reynolds and Snapp (1986) consider the case of quantity competition when firms hold partial interests in each other. Hansen and Lott (1996), mentioned in the introduction, were the first to discuss the potential effects of portfolio diversification for oligopolistic competition.

This paper also relates to the literature on aggregation of shareholder preferences, going back at least to the impossibility result of Arrow (1950). Although his 1950 paper does not apply the results to aggregation of differing shareholder preferences, this problem was in the background of the research on the impossibility theorem, as Arrow mentions later (Arrow, 1983, p. 2):

"When in 1946 I began a grandiose and abortive dissertation aimed at improving on John Hicks's Value and Capital, one of the obvious needs for generalization was the theory of the firm. What if it had many owners, instead of the single owner postulated by Hicks? To be sure, it could be assumed that all were seeking to maximize profits; but suppose they had different expectations of the future? They would then have differing preferences over investment projects. I first supposed that they would decide, as the legal framework would imply, by majority voting. In economic analysis we usually have many (in fact, infinitely many) alternative possible plans, so that transitivity quickly became a significant question. It was immediately clear that majority voting did not necessarily lead to an ordering."

Milne (1981) explicitly applies Arrow's result to the shareholders' preference aggregation problem. Under complete markets and price-taking firms, the Fisher separation theorem applies, and thus all shareholders unanimously agree on the profit maximization objective (see Milne 1974, Milne 1981). With incomplete markets, however, the preference aggregation problem is non-trivial. The literature on incomplete markets has thus studied the outcome of equilibria with shareholder voting. For example, see the work of Diamond (1967), Milne (1981), Dreze (1985), Duffie and Shafer (1986), DeMarzo (1993), Kelsey and Milne (1996), and Dierker et al. (2002). This literature keeps the price-taking assumption, so there is no potential for firms exercising market power.

An important precedent on the objectives of the firm under imperfect competition in 
general equilibrium is the work of Renstrom and Yalcin (2003), who model the objective of a monopolist whose objective is derived through shareholder voting. They use a median voter model instead of probabilistic voting theory. Their focus is on the effects of productivity differences among consumers, and on the impact of short-selling restrictions on the equilibrium outcome. Although not in a general equilibrium context, Kelsey and Milne (2008) study the objective function of the firm in imperfectly competitive markets when the control group of the firm includes consumers. They assume that an efficient mechanism exists such that firms maximize a weighted average of the utilities of the members of their control groups. The control groups can include shareholders, managers, workers, customers, and members of competitor firms. They show that, in a Cournot oligopoly model, a firm has an incentive to give influence to consumers in its decisions. They also show that in models with strategic complements, such as Bertrand competition, firms have an incentive to give some influence to representatives of competitor firms.

Another related branch of the literature is the work on general equilibrium models with oligopoly. A useful textbook treatment can be found in Myles (1995), chap. 11. For a recent contribution and a useful discussion of this class of models, see Neary (2002) and Neary (2009).

The theoretical relationship between inequality and market power has been explored in the context of monopolistic competition by Foellmi and Zweimuller (2004). They show that, when preferences are nonhomothetic, the distribution of income affects equilibrium markups and equilibrium product diversity. The channel through which this happens in their model is the effect that the income distribution has on the elasticity of demand.

From an empirical point of view, there are several related papers. Parker and Röller (1997) study the effect of cross-ownership and multimarket contact in the mobile telephone industry. In the early 1980s in the United States, the Federal Communications Commission created local duopolies in which two firms were allowed to operate in strictly defined product and geographic markets. Since before the market structure was monopolistic, this provides an interesting opportunity to study the effect of changes in market structure on prices. They find that both cross-ownership and multimarket contact led to collusive behavior. Matvos and Ostrovsky (2008) study the effect of cross-ownership on mergers and acquisitions. They cite several studies showing that acquiring shareholders, if cross-ownership is not taken into account, lose money on average. They show that the probability that an acquiring shareholder will vote for the merger increases with the level of cross-ownership in the target 
firm. This is evidence in favor of the idea that shareholders take into account the effect of decisions on the joint value of the firms in their portfolio, rather than the separate effect on each firm.

The empirical section of this paper adds common ownership variables to structureconduct-performance regressions. For a thorough review of this literature-which went out of fashion in the 1980s after failing to find a strong relationship between market structure and markups-see Schmalensee (1989).

Finally, this paper touches on themes that are present in the literature on the history of financial regulation and the origins of antitrust. DeLong (1991) studies the relationship between the financial sector and industry in the U.S. during the late nineteenth and early twentieth century. He documents that representatives of J.P. Morgan and other financial firms sat on the boards of several firms within an industry. He argues that this practice, while helping to align the interests of ownership and control, also led to collusive behavior. Roe (1996) and Becht and DeLong (2005) study the political origins of the US system of corporate governance. In particular, they focus on the weakness of financial institutions with respect to management in the US relative to other countries, especially Germany and Japan. They argue that this weakness was can be understood, at least in part, as the outcome of a political process. In the US, populist forces and the antitrust movement achieved their objective of weakening the large financial institutions that in other countries exert a tighter control over managers.

\section{The Basic Model: Oligopoly with Shareholder Vot- ing}

An oligopolistic industry consists of $N$ firms. Firm $n$ 's profits per share are random and depend both on its own policies $p_{n}$ and on the policies of the other firms, $p_{-n}$, as well as the state of nature $\omega \in \Omega$ :

$$
\pi_{n}=\pi_{n}\left(p_{n}, p_{-n} ; \omega\right)
$$

Suppose that $p_{n} \in S_{n} \subseteq \mathbb{R}^{K}$, so that policies can be multidimensional. The policies of the firm can be prices, quantities, investment decisions, innovation, or in general any decision variable that the firm needs to choose. In principle, the policies could be contingent on the state of nature, but this is not necessary. 
There is a continuum $G$ of shareholders of measure one. Shareholder $g$ holds $\theta_{n}^{g}$ shares in firm $n$. The total number of shares of each firm is normalized to 1. Each firm holds its own elections to choose the board of directors, which controls the firms' policies. In the elections of company $n$ there is Downsian competition between two parties, $A_{n}$ and $B_{n}$. Let $\xi_{J_{n}}^{g}$ denote the probability that shareholder $g$ votes for party $J_{n}$ in company $n$ 's elections, where $J_{n} \in A_{n}, B_{n}$. The expected vote share of party $J_{n}$ in firm n's elections is

$$
\xi_{J_{n}}=\int_{g \in G} \theta_{n}^{g} \xi_{J_{n}}^{g} d g
$$

Shareholders get utility from income-which is the sum of profits from all their shares-and from a random component that depends on what party is in power in each of the firms. The utility of shareholder $g$ when the policy of firm $n$ is $p_{n}$, the policies of the other firms are $p_{-n}$, and the vector of elected parties is $\left\{J_{n}\right\}_{n=1}^{N}$ is

$$
\tilde{U}^{g}\left(p_{n}, p_{-n},\left\{J_{s}\right\}_{s=1}^{N}\right)=U^{g}\left(p_{n}, p_{-n}\right)+\sum_{s=1}^{N} \tilde{\sigma}_{s}^{g}\left(J_{s}\right),
$$

where $U^{g}\left(p_{n}, p_{-n}\right)=\mathbb{E}\left[u^{g}\left(\sum_{s=1}^{N} \theta_{s}^{g} \pi_{s}\left(p_{s}, p_{-s} ; \omega\right)\right)\right]$. The utility function $u^{g}$ of each group is increasing in income, with non-increasing marginal utility. The $\tilde{\sigma}_{n}^{g}\left(J_{n}\right)$ terms represent the random utility that shareholder $g$ obtains if party $J_{n}$ controls the board of company $n$. The random utility terms are independent across firms and shareholders, and independent of the state of nature $\omega$. As a normalization, let $\tilde{\sigma}_{n}^{g}\left(A_{n}\right)=0$. I assume that, given $p_{-n}$, there is an interior $p_{n}$ that maximizes $U^{g}\left(p_{n}, p_{-n}\right)$.

Let $p_{A_{n}}$ denote the platform of party $A_{n}$ and $p_{B_{n}}$ that of party $B_{n}$.

Assumption 1. (Conditional Sincerity) Voters are conditionally sincere. That is, in each firm's election they vote for the party whose policies maximize their utilities, given the equilibrium policies in all the other firms. In case of indifference between the two parties, a voter randomizes.

Conditional sincerity is a natural assumption as a starting point in models of multiple elections. Alesina and Rosenthal (1996) obtain it as a result of coalition proof Nash equilibrium in a model of simultaneous presidential and congressional split-ticket elections. A complete characterization of the conditions under which conditional sincerity arises as the outcome of strategic voting is an open problem (for a recent contribution and discussion 
of the issues, see Ahn and Oliveros 2010). In this paper, I will treat conditional sincerity as a plausible behavioral assumption, which, while natural as a starting point, does not necessarily hold in general.

Using Assumption 1, the probability that shareholder $g$ votes for party $A_{n}$ is

$$
\xi_{A_{n}}^{g}=P\left[\tilde{\sigma}_{n}^{g}\left(B_{n}\right)<U^{g}\left(p_{A_{n}}, p_{-n}\right)-U^{g}\left(p_{B_{n}}, p_{-n}\right)\right]
$$

Let us assume that the marginal distribution of $\tilde{\sigma}_{n, i}^{g}\left(B_{n}\right)$ is uniform with support $\left[-m_{n}^{g}, m_{n}^{g}\right]$. Denote its cumulative distribution function $H_{n}^{g}$. The vote share of party $A_{n}$ is

$$
\xi_{A_{n}}=\int_{g \in G} \theta_{n}^{g} H_{n}^{g}\left[U^{g}\left(p_{A_{n}}, p_{-n}\right)-U^{g}\left(p_{B_{n}}, p_{-n}\right)\right] d g .
$$

Both parties choose their platforms to maximize their expected vote shares.

Assumption 2. (Differentiability and Concavity of Vote Shares) For all firms $n=1, \ldots, N$, the vote share of party $A_{n}$ is differentiable and strictly concave as a function of $p_{n}$ given the policies of the other firms $p_{-n}$ and the platform of party $B_{n}$. The vote share is continuous as a function of $p_{-n}$. Analogous conditions hold for the vote share of party $B_{n}$.

Elections for all companies are held simultaneously, and the two parties in each company announce their platforms simultaneously as well. A pure-strategy Nash equilibrium for the industry is a set of platforms $\left\{p_{A_{n}}, p_{B_{n}}\right\}_{n=1}^{N}$ such that, given the platform of the other party in the firm, and the winning policies in all the other firms, a party chooses its platform to maximize its vote share. The first-order condition for party $A_{n}$ is

$$
\int_{g \in G} \frac{1}{2 m_{n}^{g}} \theta_{n}^{g} \frac{\partial U^{g}\left(p_{A_{n}}, p_{-n}\right)}{\partial p_{A_{n}}} d g=0
$$

where

$$
\frac{\partial U^{g}\left(p_{n}, p_{-n}\right)}{\partial p_{A_{n}}}=\left(\frac{\partial U^{g}\left(p_{A_{n}}, p_{-n}\right)}{\partial p_{A_{n}}^{1}}, \ldots, \frac{\partial U^{g}\left(p_{A_{n}}, p_{-n}\right)}{\partial p_{A_{n}}^{K}}\right)
$$

In the latter expression, $p_{A_{n}}^{k}$ is the $k$ th component of the policy vector $p_{A_{n}}$. The derivatives in terms of the profit functions are

$$
\frac{\partial U^{g}\left(p_{n}, p_{-n}\right)}{\partial p_{A_{n}}}=\mathbb{E}\left[\left(u^{g}\right)^{\prime}\left(\sum_{s=1}^{N} \theta_{s}^{g} \pi_{s}\left(p_{s}, p_{-s} ; \omega\right)\right) \sum_{s=1}^{N} \theta_{s}^{g} \frac{\partial \pi_{s}\left(p_{s}, p_{-s}\right)}{\partial p_{n}}\right]
$$


The maximization problem for party $B_{n}$ is symmetric. Because the individual utility functions have an interior maximum, the problem of maximizing vote shares given the policies of the other firms will also have an interior solution.

To ensure that an equilibrium in the industry exists, we need an additional technical assumption.

Assumption 3. The strategy spaces $S_{n}$ are nonempty compact convex subsets of $\mathbb{R}^{K}$.

Theorem 1. Suppose that Assumptions 1, 2, and 3 hold. Then, a pure-strategy equilibrium of the voting game exists. The equilibrium is symmetric in the sense that $p_{A_{n}}=p_{B_{n}}=p_{n}^{*}$ for all $n$. The equilibrium policies solve the system of $N \times K$ equations in $N \times K$ unknowns

$$
\int_{g \in G} \frac{1}{2 m_{n}^{g}} \theta_{n}^{g} \frac{\partial U^{g}\left(p_{n}^{*}, p_{-n}^{*}\right)}{\partial p_{n}} d g=0 \text { for } n=1, \ldots, N
$$

Proof. Consider the election at firm $n$, given that the policies of the other firms are equal to $p_{-n}$. Given the conditional sincerity assumption, the vote share of party $A_{n}$ is as in equation (1), and a similar expression holds for the vote share of party $B_{n}$. As we have already noted, each party's maximization problem has an interior solution conditional on $p_{-n}$. The firstorder conditions for each party are the same, and thus the best responses for both parties are the same. We can think of the equilibrium at firm $n$ 's election given the policies of the other firms as establishing a reaction function for the firm, $p_{n}\left(p_{-n}\right)$. These reaction functions are nonempty, upper-hemicontinuous, and convex-valued. Thus, we can apply Kakutani's fixed point theorem to show that an equilibrium exists, in a way that is analogous to that of existence of Nash equilibrium in games with continuous payoffs.

The system of equations in (3) corresponds to the solution to the maximization of the following utility functions

$$
\int_{g \in G} \chi_{n}^{g} \theta_{n}^{g} U^{g}\left(p_{n}, p_{-n}\right) d g \text { for } n=1, \ldots, N
$$

where the $n$th function is maximized with respect to $p_{n}$, and where $\chi_{n}^{g} \equiv \frac{1}{2 m_{n}^{g}}$. Thus, the equilibrium for each firm's election is characterized by the maximization of a weighted average of the utilities of its shareholders. The weight that each shareholder gets at each firm depends both on the number of shares held in that firm, and on the dispersion of the 
random utility component for that firm. Note that the weights in the average of shareholder utilities are different at different firms.

The maximization takes into account the effect of the policies of firm $n$ on the profits that shareholders get from every firm, not just firm $n$. Thus, when the owners of a firm are also the residual claimants for other firms, they internalize some of the pecuniary externalities that the actions of the first firm generate for the other firms that they hold.

\section{The Case of Complete Diversification}

We will find it useful to define the following concepts:

Definition 1. (Market Portfolio) A market portfolio is any portfolio that is proportional to the total number of shares of each firm. Since we have normalized the number of shares of each firm to one, a market portfolio has the same number of shares in every firm.

Definition 2. (Complete Diversification) We say that a shareholder who holds a market portfolio is completely diversified.

Definition 3. (Uniformly Activist Shareholders) We say that a shareholder is uniformly activist if the density of the distribution of $\tilde{\sigma}_{n}^{g}\left(B_{n}\right)$ is the same for every firm $n$.

Shareholders having a high density of $\tilde{\sigma}_{n}^{g}\left(B_{n}\right)$ have a higher weight in the equilibrium policies of firm $n$ for a given number of shares. Thus, we can think of shareholders having high density as being more "activist" when it comes to influencing the decisions of that firm. If all shareholders are uniformly activist, then some shareholders can be more activist than others, but the level of activism for each shareholder is constant across firms.

Theorem 2. Suppose all shareholders are completely diversified, and shareholders are uniformly activist. Then the equilibrium of the voting game yields the same outcome as the one that a monopolist who owned all the firms and maximized a weighted average of the utilities of the shareholders would choose.

Proof. Because of complete diversification, a shareholder $g$ holds the same number of shares $\theta^{g}$ in each firm. The equilibrium now corresponds to the solution of

$$
\max _{p_{n}} \int_{g \in G} \chi_{n}^{g} \theta^{g} U^{g}\left(p_{n}, p_{-n}\right) d g \text { for } n=1, \ldots, N
$$


With the assumption that shareholders are uniformly activist, $\chi_{n}^{g}$ is the same for every firm, and thus the objective function is the same for all $n$. The problem can thus be rewritten as

$$
\max _{\left\{p_{n}\right\}_{n=1}^{N}} \int_{g \in G} \chi^{g} \theta^{g} U^{g}\left(p_{n}, p_{-n}\right) d g
$$

This is the problem that a monopolist would solve, if her utility function was a weighted average of the utilities of the shareholders. The weight of shareholder $g$ is equal to $\chi^{g} \theta^{g}$.

Note that, although all the shareholders hold proportional portfolios, there is still a conflict of interest between them. This is due to the fact that there is uncertainty and shareholders, unless they are risk neutral, care about the distribution of joint profits, not just the expected value. For example, they may have different degrees of risk aversion, both because some may be wealthier than others (i.e. hold a bigger share of the market portfolio), or because their utility functions differ. Thus, although all shareholders are fully internalizing the pecuniary externalities that the actions of each firm generates on the profits of the other firms, some may want the firms to take on more risks, and some may want less risky actions. Thus, there is still a non-trivial preference aggregation problem. In what follows, I will show that when shareholders are risk neutral, or when there is no uncertainty, then there is no conflict of interest between shareholders: they all want the firms to implement the same policies.

We will now show that, when all shareholders are completely diversified and risk neutral, the solution can be characterized as that of a profit-maximizing monopolist. In this case, we do not need the condition that $\chi_{n}^{g}$ is independent of $n$. In fact, in this case, there is no conflict of interest between shareholders, since they uniformly agree on the objective of expected profit maximization. Thus, this result is likely to hold in much more general environments than the probabilistic voting model of this paper.

Theorem 3. Suppose all shareholders are completely diversified, and their preferences are risk neutral. Then the equilibrium of the voting game yields the same outcome as the one that a monopolist who owned all the firms and maximized their joint expected profits would choose.

Proof. Let the utility function of shareholder $g$ be $u^{g}(y)=a^{g}+b^{g} y$. Then the equilibrium 
is characterized by the solution of

$$
\max _{p_{n}} \int_{g \in G} \chi_{n}^{g} \theta^{g}\left\{a^{g}+b^{g} \mathbb{E}\left[\sum_{s=1}^{N} \theta^{g} \pi_{s}\left(p_{s}, p_{-s} ; \omega\right)\right]\right\} d g \text { for } n=1, \ldots, N
$$

which can be rewritten as

$$
\max _{p_{n}} k_{0, n}+k_{1, n} \mathbb{E}\left[\sum_{s=1}^{N} \pi_{s}\left(p_{s}, p_{-s} ; \omega\right)\right] \text { for } n=1, \ldots, N
$$

with $k_{0, n}=\int_{g \in G} \chi_{n}^{g} \theta^{g} a^{g} d g$ and $k_{1, n}=\int_{g \in G} \chi_{n}^{g}\left(\theta^{g}\right)^{2} b^{g} d g$. Since $k_{1, n}$ is positive, this is the same as maximizing

$$
\mathbb{E}\left[\sum_{s=1}^{N} \pi_{s}\left(p_{s}, p_{-s} ; \omega\right)\right]
$$

which is the expected sum of profits of all the firms in the industry. Since the objective function is the same for every firm, we can rewrite this as

$$
\max _{\left\{p_{n}\right\}_{n=1}^{N}} \mathbb{E}\left[\sum_{s=1}^{N} \pi_{s}\left(p_{s}, p_{-s} ; \omega\right)\right]
$$

The intuition behind this result is simple. When shareholders are completely diversified, their portfolios are identical, up to a constant of proportionality. Without risk neutrality, shareholders cared not just about expected profits, but about the whole distribution of joint profits. With risk neutrality, however, shareholders only care about joint expected profits, and thus the conflict of interest between shareholders disappears. The result is that they unanimously want maximization of the joint expected profits, and the aggregation problem becomes trivial.

Finally, let us consider the case of no uncertainty. In this case, when shareholders are completely diversified there is also no conflict of interest between them, and they unanimously want the maximization of joint profits. This is similar to the case of risk neutrality. As in that case, because preference are unanimous the result is likely to hold under much more general conditions.

Theorem 4. Suppose all shareholders are completely diversified, and there is no uncertainty. 
Then the equilibrium of the voting game yields the same outcome as the one that a monopolist who owned all the firms and maximized their joint profits would choose.

Proof. To see why this is the case, note that the outcome of the voting equilibrium is characterized by the solution to

$$
\max _{p_{n}} \int_{g \in G} \chi_{n}^{g} \theta^{g} u^{g}\left(\theta^{g} \sum_{s=1}^{N} \pi_{s}\left(p_{s}, p_{-s}\right)\right) d g \text { for } n=1, \ldots, N
$$

We can rewrite this as

$$
\max _{p_{n}} f_{n}\left(\sum_{s=1}^{N} \pi_{s}\left(p_{s}, p_{-s}\right)\right) \text { for } n=1, \ldots, N
$$

where

$$
f_{n}(z)=\int_{g \in G} \chi_{n}^{g} \theta^{g} u^{g}\left(\theta^{g} z\right) d g .
$$

Since $f_{n}(z)$ is monotonically increasing, the solution to is equivalent to

$$
\max _{p_{n}} \sum_{s=1}^{N} \pi_{s}\left(p_{s}, p_{-s}\right) \text { for } n=1, \ldots, N
$$

Because the objective function is the same for all firms, we can rewrite this as

$$
\max _{\left\{p_{n}\right\}_{n=1}^{N}} \sum_{s=1}^{N} \pi_{s}\left(p_{s}, p_{-s}\right)
$$

The intuition is similar to that of Theorem 3: when all shareholders are completely diversified and there is no uncertainty, then there is no conflict of interest among them, and the aggregation problem becomes trivial. Thus, in the special case of complete diversification and either risk-neutral shareholders or certainty, shareholders are unanimous in their support for joint profit maximization as the objective of the firm, as argued by Hansen and Lott (1996). 


\section{An Example: Quantity and Price Competition}

In this section, I illustrate the previous results by applying the general model to the classical oligopoly models of Cournot and Bertrand with linear demands and constant marginal costs. I consider both the homogeneous goods and the differentiated goods variants of these models. For the case of differentiated goods, I use the model of demand developed by Dixit (1979) and Singh and Vives (1984), and extended to the case of an arbitrary number of firms by Häckner (2000).

There is no uncertainty in these models, and I will assume that agents are risk neutral. I will also assume that the $\tilde{\sigma}_{s, i}^{g}\left(J_{s}\right)$ are uniformly distributed between $-\frac{1}{2}$ and $\frac{1}{2}$ for all firms and all shareholders. Thus, the cumulative distribution function $H_{n}^{g}(x)$ is given by

$$
H_{n}^{g}(x)=\left\{\begin{array}{cl}
0 & \text { if } x \leq-\frac{1}{2} \\
x+\frac{1}{2} & \text { if }-\frac{1}{2}<x \leq \frac{1}{2} \\
1 & \text { if } x \geq \frac{1}{2}
\end{array}\right.
$$

\subsection{Homogeneous Goods}

\subsubsection{Homogeneous Goods Cournot}

The inverse demand for a homogeneous good is $P=\alpha-\beta Q$. In the Cournot model, firms set quantities given the quantities of other firms. The marginal cost is constant and equal to $m$. Each firm's profit function, given the quantities of other firms is

$$
\pi_{n}\left(q_{n}, q_{-n}\right)=\left[\alpha-\beta\left(q_{n}+q_{-n}\right)-m\right] q_{n}
$$

The vote share of party $A_{n}$ when the policies of both parties are close to each other is

$$
\xi_{A_{n}}=\int_{g \in G} \theta_{n}^{g}\left\{\frac{1}{2}+\left[U^{g}\left(q_{A_{n}}, q_{-n}\right)-U^{g}\left(q_{B_{n}}, q_{-n}\right)\right]\right\} d g
$$

where $U^{g}\left(q_{n}, q_{-n}\right)=\sum_{s=1}^{N} \theta_{s}^{g}\left[\alpha-\beta\left(q_{s}+q_{-s}\right)-m\right] q_{s}$. The vote share is strictly concave as a function of $q_{A_{n}}$, and thus the maximization problem for party $A_{n}$ has an interior solution. The maximization problem for party $B_{n}$ is symmetric. Thus, we can apply Theorem 1 to obtain the following result:

Proposition 1. In the homogeneous goods Cournot model with shareholder voting as de- 
scribed above, a symmetric equilibrium exists. The equilibrium quantities in the industry solve the following linear system of $N$ equations and $N$ unknowns:

$$
\int_{g \in G} \theta_{n}^{g}\left[\theta_{n}^{g}\left(\alpha-2 \beta q_{n}-\beta q_{-n}-m\right)+\sum_{s \neq n} \theta_{s}^{g}\left(-\beta q_{s}\right)\right] d g=0 \text { for } n=1, \ldots, N
$$

To visualize the behavior of the equilibria for different levels of diversification, I will parameterize the latter as follows. Shareholders are divided in $N$ groups, each with mass $1 / N$. The portfolios can be organized in a square matrix, where the element of row $j$ and column $n$ is $\theta_{n}^{j}$. Thus, row $j$ of the matrix represents the portfolio holdings of a shareholder in group $j$. When this matrix is diagonal with each element of the diagonal equal to $N$, shareholders in group $n$ owns all the shares of firm $n$, and has no stakes in any other firm. Call this matrix of portfolios $\Theta_{0}$ :

$$
\Theta_{0}=\left[\begin{array}{cccc}
N & 0 & \cdots & 0 \\
0 & N & \cdots & 0 \\
\vdots & \vdots & \ddots & \vdots \\
0 & 0 & \cdots & N
\end{array}\right]
$$

In the other extreme, when each fund holds the market portfolio, each element of the matrix is equal to 1 . Call this matrix $\Theta_{1}$ :

$$
\Theta_{1}=\left[\begin{array}{cccc}
1 & 1 & \cdots & 1 \\
1 & 1 & \cdots & 1 \\
\vdots & \vdots & \ddots & \vdots \\
1 & 1 & \cdots & 1
\end{array}\right] .
$$

I will parameterize intermediate cases of diversification by considering convex combinations of these two:

$$
\Theta_{\phi}=(1-\phi) \Theta_{0}+\phi \Theta_{1}
$$

where $\phi \in[0,1]$. Thus, when $\phi=0$, we are in the classical oligopoly model in which each firm is owned independently. When $\phi=1$ the firms are held by perfectly diversified shareholders, each holding the market portfolio.

Figure 2 shows the equilibrium prices and total quantities of the Cournot model with 
homogeneous goods for different levels of diversification and different numbers of firms. The parameters are $\alpha=\beta=1$ and $m=0$. It can be seen that, as portfolios become closer to the market portfolio, the equilibrium prices and quantities tend to the monopoly outcome. This does not depend on the number of firms in the industry.

\subsubsection{Homogeneous Goods Bertrand}

The case of price competition with homogeneous goods is interesting because the profit functions are discontinuous, and the parties' maximization problems do not have interior solutions. Thus, we cannot use the equations of Theorem 1 to solve for the equilibrium. However, by studying the vote shares of the parties, we can show that symmetric equilibria exist, and lead to a result similar to the Bertrand paradox. When portfolios are completely diversified, any price between marginal cost and the monopoly price can be sustained in equilibrium. However, any deviation from the market portfolio by a group of investors, no matter how small, leads to undercutting, and thus the only possible equilibrium is price equal to marginal cost.

The demand for the homogeneous good is $Q=a-b P$, where $a=\frac{\alpha}{\beta}$ and $b=\frac{1}{\beta}$. The firm with the lowest price attracts all the market demand. At equal prices, the market splits in equal parts. When a firm's price $p_{n}$ is the lowest in the market, it gets profits equal to $\left(p_{n}-m\right)\left(a-b p_{n}\right)$. If a firms' price is tied with $M-1$ other firms, its profits are $\frac{1}{M}\left(p_{n}-m\right)\left(a-b p_{n}\right)$.

It will be useful to define the profits that a firm setting a price $p$ would make if it attracted all the market demand at that price:

$$
\tilde{\pi}(p) \equiv(p-m)(a-b p)
$$

The vote share of party $A_{n}$ when the policies of both parties are close to each other is

$$
\xi_{A_{n}}=\int_{g \in G} \theta_{n}^{g}\left\{\frac{1}{2}+\left[U^{g}\left(p_{A_{n}}, p_{-n}\right)-U^{g}\left(p_{B_{n}}, p_{-n}\right)\right]\right\} d g,
$$

where $U^{g}\left(p_{n}, p_{-n}\right)=\sum_{s=1}^{N} \theta_{s}^{g} \pi\left(p_{s}, p_{-s}\right)$. Note that the profit function is discontinuous, and thus, as already mentioned, we cannot use Theorem 1 to ensure the existence and characterize the equilibrium. However, equilibria do exist, and we can show the following result:

Proposition 2. In the homogeneous goods Bertrand model with shareholder voting described 
above, symmetric equilibria exist. When all shareholders hold the market portfolio (except for a set of shareholders of measure zero), any price between the marginal cost and the monopoly price can be sustained as an equilibrium. If a set of shareholders with positive measure is incompletely diversified, the only equilibrium is when all firms set prices equal to the marginal cost.

Proof. First, it will be useful to define the following. The average of the holdings for shareholder $g$ is

$$
\overline{\theta^{g}} \equiv \frac{1}{N} \sum_{n=1}^{N} \theta_{n}^{g}
$$

The average of the squares of the holdings for shareholder $g$ is

$$
\overline{\left(\theta^{g}\right)^{2}} \equiv \frac{1}{N} \sum_{n=1}^{N}\left(\theta_{n}^{g}\right)^{2}
$$

Let us begin with the case of all shareholders holding the market portfolio. In this case, $\theta_{n}^{g}=\overline{\theta^{g}}$ for all $n$. Consider the situation of party $A_{n}$. Suppose all other firms, and party $B_{n}$ have set a price $p^{*} \in\left[m, p^{M}\right]$, where $p^{M}$ is the monopoly price. Maximizing the vote share of party $A_{n}$ is equivalent to maximizing

$$
\int_{g \in G} \overline{\theta^{g}}\left(\sum_{s=1}^{N} \overline{\theta^{g}} \pi\left(p_{s}, p_{-s}\right)\right) d g=\left(\sum_{s=1}^{N} \pi\left(p_{s}, p_{-s}\right)\right) \int_{g \in G}{\overline{\theta^{g}}}^{2} d g
$$

which is a constant times the sum of profits for all firms. Thus, to maximize its vote share, party $A_{n}$ will choose the price that maximizes the joint profits of all firms, given that the other firms have set prices equal to $p^{*}$. Setting a price equal to $p^{*}$ maximizes joint profits, as does any price above it. Any price below $p^{*}$ would reduce joint profits, and thus there is no incentive to undercut. Therefore, all parties in all firms choosing $p^{*}$ as a platform is a symmetric equilibrium, for any $p^{*} \in\left[m, p^{M}\right]$.

Now, let's consider the case of incomplete diversification. It is easy to show that all firms setting price equal to $m$ is an equilibrium, since there is no incentive to undercut. I will now show that firms setting prices above $m$ can't be an equilibrium. Suppose that there is an equilibrium with all firms setting the same price $p^{*} \in\left(m, p^{M}\right]$. Maximizing vote share for 
any of the parties at firm $n$ is equivalent to maximizing

$$
\int_{g \in G} \theta_{n}^{g}\left(\sum_{s=1}^{N} \theta_{s}^{g} \pi\left(p_{s}, p_{-s}\right)\right) d g
$$

If firm $n$ charges $p^{*}$, the profits of each firm are $\frac{1}{N} \pi\left(p^{*}\right)$. If firm $n$ undercuts, that is, if it charges a price equal to $p^{*}-\epsilon$, then the profits of all the other firms are driven to zero, and its own profits are $\pi\left(p^{*}-\epsilon\right)$, which can be made arbitrarily close to $\pi\left(p^{*}\right)$.

Thus, firm $n$ will not undercut if and only if

$$
\int_{g \in G} \theta_{n}^{g}\left(\sum_{s=1}^{N} \theta_{s}^{g} \frac{\pi\left(p^{*}\right)}{N}\right) d g \geq \int_{g \in G}\left(\theta_{n}^{g}\right)^{2} \pi\left(p^{*}\right) d g .
$$

We can simplify this inequality to obtain the following condition:

$$
\int_{g \in G} \theta_{n}^{g}\left(\overline{\theta^{g}}-\theta_{n}^{g}\right) d g \geq 0
$$

We can show by contradiction that at least one firm will undercut. Suppose not. Then the above inequality holds for all $n$. Adding across firms yields

$$
\sum_{n=1}^{N} \int_{g \in G} \theta_{n}^{g}\left(\overline{\theta^{g}}-\theta_{n}^{g}\right) d g \geq 0 .
$$

Exchanging the order of summation and integration, we obtain

$$
\int_{g \in G} \sum_{n=1}^{N} \theta_{n}^{g}\left(\overline{\theta^{g}}-\theta_{n}^{g}\right) d g \geq 0
$$


But each term $\sum_{n=1}^{N} \theta_{n}^{g}\left(\overline{\theta^{g}}-\theta_{n}^{g}\right)$ is negative, since

$$
\begin{aligned}
\sum_{n=1}^{N} \theta_{n}^{g}\left(\overline{\theta^{g}}-\theta_{n}^{g}\right) & =\sum_{n=1}^{N} \theta_{n}^{g}\left(\overline{\theta^{g}}-\theta_{n}^{g}\right) \\
& =\left(N\left(\overline{\theta^{g}}\right)^{2}-N \overline{\left(\theta^{g}\right)^{2}}\right) \\
& =-N\left(\overline{\left(\theta^{g}\right)^{2}}-\left(\overline{\theta^{g}}\right)^{2}\right) \\
& =-N \frac{1}{N} \sum_{n=1}^{N}\left(\theta_{n}^{g}-\overline{\theta^{g}}\right)^{2} \\
& \leq 0 .
\end{aligned}
$$

Equality holds if and only if $\frac{1}{N} \sum_{n=1}^{N}\left(\theta_{n}^{g}-\overline{\theta^{g}}\right)^{2}=0$, which only happens when shareholders are completely diversified, except for a set of measure zero. To avoid a contradiction, all the terms would have to be zero. This only happens when all shareholders are completely diversified except for a set of measure zero, which contradicts the hypothesis. Thus, when diversification is incomplete, at least one firm will undercut. The only possible equilibrium in the case of incomplete diversification is with all firms setting price equal to marginal cost.

\subsection{Differentiated Goods}

In this section, I apply the voting model to the case of price and quantity competition with differentiated goods. I use the demand model of Häckner (2000), and in particular the symmetric specification described in detail in Ledvina and Sircar (2010). The utility function in this model is

$$
U(q)=\alpha \sum_{n=1}^{N} q_{n}-\frac{1}{2}\left(\beta \sum_{n=1}^{N} q_{n}^{2}+2 \gamma \sum_{s \neq n} q_{n} q_{s}\right) .
$$

The representative consumer maximizes $U(q)-\sum p_{n} q_{n}$. The first-order conditions with respect to $n_{s}$ is

$$
\frac{\partial U}{\partial q_{n}}=\alpha-\beta q_{n}-\gamma \sum_{s \neq n} q_{s}-p_{n}=0
$$




\subsubsection{Differentiated Goods Cournot}

The inverse demand curve for firm $n$ is

$$
p_{n}\left(q_{n}, q_{-n}\right)=\alpha-\beta q_{n}-\gamma \sum_{s \neq n} q_{s}
$$

The profit function for firm $n$ is

$$
\pi_{n}\left(q_{n}, q_{-n}\right)=\left(\alpha-\beta q_{n}-\gamma \sum_{s \neq n} q_{s}-m\right) q_{n}
$$

The vote share of party $A_{n}$ is as in equation (7), with the utility of shareholder $g$ being

$$
U^{g}\left(q_{n}, q_{-n}\right)=\sum_{s=1}^{N} \theta_{s}^{g}\left(\alpha-\beta q_{s}-\gamma \sum_{j \neq s} q_{j}-m\right) q_{s}
$$

As in the homogeneous goods case, the vote share is strictly concave as a function of $q_{A_{n}}$, and thus the maximization problem for party $A_{n}$ has an interior solution. The maximization problem for party $B_{n}$ is symmetric. Thus, we can apply Theorem 1 to obtain the following result:

Proposition 3. In the differentiated goods Cournot model with shareholder voting as described above, a symmetric equilibrium exists. The equilibrium quantities in the industry solve the following linear system of $N$ equations and $N$ unknowns:

$$
\int_{g \in G} \theta_{n}^{g}\left[\theta_{n}^{g}\left(\alpha-2 \beta q_{n}-\gamma \sum_{s \neq n} q_{s}-m\right)+\sum_{s \neq n} \theta_{s}^{g}\left(-\gamma q_{s}\right)\right] d g=0 \text { for } n=1, \ldots, N \text {. }
$$

\subsubsection{Differentiated Goods Bertrand}

As in Ledvina and Sircar (2010), the demand system can be inverted to obtain the demands

$$
q_{n}\left(p_{n}, p_{-n}\right)=a_{N}-b_{N} p_{n}+c_{N} \sum_{s \neq n} p_{s} \text { for } n=1, \ldots, N
$$


where, for $1 \leq n \leq N$, and defining

$$
\begin{gathered}
a_{n}=\frac{\alpha}{\beta+(n-1) \gamma}, \\
b_{n}=\frac{\beta+(n-2) \gamma}{(\beta+(n-1) \gamma)(\beta-\gamma)}, \\
c_{n}=\frac{\gamma}{(\beta+(n-1) \gamma)(\beta-\gamma)} .
\end{gathered}
$$

The profits of firm $n$ are

$$
\pi_{n}\left(p_{n}, p_{-n}\right)=\left(p_{n}-m\right)\left(a_{N}-b_{N} p_{n}+c_{N} \sum_{s \neq n} p_{s}\right)
$$

The vote share of party $A_{n}$ is as in (7), with the utility of shareholder $g$ being

$$
U^{g}\left(p_{n}, p_{-n}\right)=\sum_{s=1}^{N} \theta_{s}^{g}\left(p_{s}-m\right)\left(a_{N}-b_{N} p_{s}+c_{N} \sum_{j \neq s} p_{j}\right) .
$$

The vote share is strictly concave as a function of $p_{A_{n}}$, and thus the maximization problem for party $A_{n}$ has an interior solution. The maximization problem for party $B_{n}$ is symmetric. Thus, we can apply Theorem 1 to obtain the following result:

Proposition 4. In the differentiated goods Bertrand model with shareholder voting as described above, a symmetric equilibrium exists. The equilibrium quantities in the industry solve the following linear system of $N$ equations and $N$ unknowns:

$$
\int_{g \in G} \theta_{n}^{g}\left[\theta_{n}^{g}\left(\left(a_{N}-b_{N} p_{n}+c_{N} \sum_{s \neq n} p_{s}\right)-b_{N}\left(p_{n}-m\right)\right)+\sum_{s \neq n} \theta_{s}^{g} c_{N}\left(p_{s}-m\right)\right] d g=0
$$

Figure 3 shows the equilibrium prices of the differentiated goods Cournot and Bertrand models for different levels of diversification and different numbers of firms. The parameters are $\alpha=\beta=1, \gamma=\frac{1}{2}$, and $m=0$. As in the case of Cournot with homogeneous goods, prices go to the monopoly prices as the portfolios go to the market portfolio. As before, this does not depend on the number of firms. ${ }^{4}$

\footnotetext{
${ }^{4}$ In this example, because goods are substitutes, price competition is more intense than quantity compe-
} 


\section{Introducing Shareholder Voting in General Equilib- rium Models with Oligopoly}

In general equilibrium models with complete markets and perfect competition, the profit maximization assumption is justified by the Fisher separation theorem. The theorem, however, does not apply to models with imperfect competition. The profit maximization assumption could be justified in partial equilibrium models of oligopoly if firms were separately owned, although this is usually an unrealistic scenario. In general equilibrium, because ownership structure is endogenous, the microfoundations for the profit maximization assumption are even shakier. In this section I show how to integrate the probabilistic voting model in a simple general equilibrium oligopoly setting.

\subsection{Model Setup}

There is a continuum $G$ of consumer-shareholders of measure one. For simplicity, I will assume that there is no uncertainty, although this can be easily relaxed. Utility is quasilinear:

$$
U(x, y)=u(x)+y
$$

To obtain closed form solutions for the oligopolistic industry equilibrium, we will also assume that $u(x)$ is quadratic:

$$
u(x)=\alpha x-\frac{1}{2} \beta x^{2} .
$$

There are $N$ oligopolistic firms producing good $x$. Each unit requires $m$ labor units to produce. They compete in quantities. There is also a competitive sector which produces good $y$, which requires 1 labor unit to produce. Each agent's time endowment is equal to 1 and labor is supplied inelastically. The wage is normalized to 1 . As is standard in oligopolistic general equilibrium models, there is no entry.

The agents are born with an endowment of shares in the $N$ oligopolistic firms (they could also have shares in the competitive sector firms, but this is irrelevant). To simplify the exposition of the initial distribution of wealth, I will assume that the agents are born with a diversified portfolios, but this is not necessary. Their initial wealth $W^{g}$ has a cumulative

tition, and thus prices are lower in the former case. Häckner (2000) showed that, in an asymmetric version of this model, when goods are complements and quality differences are sufficiently high, the prices of some firms may be higher under price competition than under quantity competition. 
distribution $F\left(W^{g}\right)$, where $W^{g}$ denotes the percentage of each firm that agent $g$ is born with. Because in equilibrium the price of all the firms is the same, this can be interpreted as the percentage of the economy's wealth that agent $g$ initially owns.

There are three stages. In the first stage, agents trade their shares. In the second, they vote over policies. In the third stage they make consumption decisions. Because there is no uncertainty, the agents are indifferent over any portfolio choice. However, adding even an infinitesimal amount of diversifiable uncertainty would lead to complete portfolio diversification, and thus we will assume that, in the case of indifference, the agents choose diversified portfolios. The equilibrium price of a company's stock will be the value of share of the profits that the stock awards the right to. This, of course, wouldn't be the true in the case of uncertainty. The key idea, however, is that asset pricing proceeds as usual: voting power is not incorporated in the price because agents are atomistic. Thus, we are assuming that there is a borrowing constraint, although not a very restrictive one: atomistic agents cannot borrow non-atomistic amounts.

In the second stage, the voting equilibrium will be as in the partial equilibrium case, with the caveat that shareholders now also consume the good that the firms produce. This will lead to an interesting relationship between the wealth distribution and the equilibrium outcome. With a completely egalitarian distribution, the equilibrium will be Pareto efficient. With wealth inequality, the equilibrium will not be Pareto efficient.

\subsection{Voting Equilibrium with Consumption}

I assume that $\chi_{n}^{g}=1$ for all shareholders and firms. Therefore, in the voting equilibrium each firm will maximize a weighted average of shareholder-consumer utilities, with weights given by their shares in the firm. The voting equilibrium for firm $n$ given the policies of the other firms is given by:

$$
\max _{q_{n}} \int_{g \in G} \theta_{n}^{g}\left\{\sum_{s=1}^{N} \theta_{s}^{g} \pi_{s}\left(q_{s}, q_{-s}\right)+v\left[\alpha-\beta\left(q_{n}+q_{-n}\right)\right]\right\} d g,
$$

where $v(P)$ is the indirect utility function from consumption of $x$ when price is $P$ :

$$
v(P)=\alpha(a-b P)-\frac{1}{2} \beta(a-b P)^{2}-P(a-b P),
$$


where $a=\frac{\alpha}{\beta}$ and $b=\frac{1}{\beta}$. This expression can be simplified to

$$
v(P)=\frac{\beta}{2}(a-b P)^{2}
$$

When shareholders are completely diversified, the equilibrium will be collusive, and can be solved for by solving the joint maximization of the weighted average of shareholder-consumer utilities:

$$
\max _{\left\{q_{n}\right\}_{n=1}^{N}} \int_{g \in G} \theta^{g}\left\{\sum_{s=1}^{N} \theta^{g} \pi_{s}\left(q_{s}, q_{-s}\right)+v\left[\alpha-\beta\left(q_{n}+q_{-n}\right)\right]\right\} d g .
$$

We can further simplify the problem by rewriting it as

$$
\max _{Q} \int_{g \in G} \theta^{g}\left\{\theta^{g} \pi(Q)+v[\alpha-\beta Q]\right\} d g
$$

where $\pi(Q)$ represents the profit function of a monopolist:

$$
\pi(Q)=(\alpha-\beta Q-m) Q
$$

Definition 4. (Completely Egalitarian Wealth Distribution) We say that the initial wealth distribution is completely egalitarian if and only if $\theta^{g}$ is constant, and equal to one for all $g$.

Theorem 5. In the oligopolistic general equilibrium model with probabilistic voting and quasilinear and quadratic utility, the outcome is Pareto efficient if and only if the initial wealth distribution is completely egalitarian.

Proof. Let's start by showing that when the distribution is completely egalitarian, the outcome is Pareto efficient. An egalitarian wealth distribution implies that $\theta^{g}=1$ for all $g$. Thus, the equilibrium is characterized by

$$
\max _{Q} \pi(Q)+v[\alpha-\beta Q] .
$$

It is straightforward to check that the solution implies that $\alpha-\beta Q=m$. That is, equilibrium price equals marginal cost, which is the condition for Pareto efficiency in this model.

Now let's show that when the outcome is Pareto efficient, the distribution of wealth is not egalitarian. Suppose not. Then there is a wealth distribution such that $\theta^{g} \neq 1$ in a set 
with positive measure. The equilibrium characterization can be rewritten as

$$
\max _{Q} \pi(Q) \int_{g \in G}\left(\theta^{g}\right)^{2} d g+v[\alpha-\beta Q]
$$

The difference between price and marginal cost in this case can be characterized by

$$
P-m=\frac{\phi-1}{\phi} \beta Q
$$

where

$$
\phi \equiv \int_{g \in G}\left(\theta^{g}\right)^{2} d g
$$

Thus, price equals marginal cost if and only if either $Q=0$ or $\phi=1$. Let us ignore the cases in which quantity equals zero, which are uninteresting. Note that $\phi-1$ is equal to the variance of $\theta^{g}$ :

$$
\sigma_{\theta}^{2}=\int_{g \in G}\left(\theta^{g}\right)^{2} d g-\left(\int_{g \in G} \theta^{g} d g\right)^{2}=\phi-1 .
$$

Therefore, if the outcome is Pareto efficient, then the variance of the distribution of shares is equal to zero, which is the same as saying that the initial wealth distribution is completely egalitarian.

It is also possible to show that there is an increasing and monotonic relationship between the variance of the wealth distribution and the equilibrium markup:

Theorem 6. In the oligopolistic general equilibrium model with probabilistic voting and quasilinear and quadratic utility, equilibrium markups are an increasing function of the variance of the wealth distribution. In the limit, as the variance of the wealth distribution goes to infinity, the equilibrium price is equal to the classic monopoly case.

Proof. We will show that prices are increasing in the variance of $\theta^{g}$. The equilibrium price is characterized by

$$
P=\frac{\alpha \frac{\sigma_{\theta}^{2}}{\sigma_{\theta}^{2}+1}+m}{\frac{\sigma_{\theta}^{2}}{\sigma_{\theta}^{2}+1}+1} .
$$

The derivative of this expression with respect to $\sigma_{\theta}^{2}$ is positive when $\alpha>m$. Cases with $\alpha<m$ are degenerate, since the valuation of $x$ would be less than its marginal cost even at zero units of consumption. 
When the variance of the wealth distribution goes to infinity, $\frac{\sigma_{\theta}^{2}}{\sigma_{\theta}^{2}+1}$ goes to 1 , and the expression becomes

$$
\lim _{\sigma_{\theta}^{2} \rightarrow \infty} P=\frac{\alpha+m}{2},
$$

which is the equilibrium price in the standard monopoly case.

Because the deadweight loss is increasing in price, the level of inefficiency will be higher for higher levels of wealth inequality. Figure 4 illustrates this results for $\alpha=1, \beta=1$ and $m=.5$.

When interpreting these results, there are several caveats that need to be noted. First, introducing in the model an endogenous labor supply and many periods, the redistribution policies required to achieve an egalitarian distribution of wealth would be distortionary, through the usual channels. Second, the model abstracts from agency issues and, with an egalitarian distribution of wealth, ownership would be extremely dispersed, making the accumulation of managerial power an important issue.

It is clear, however, that the classic trade-off between equality and efficiency does not apply in oligopolistic economies. Given the caveats mentioned in the last paragraph, it is possible that for some regions of the parameter space, and for some levels of inequality, a reduction in inequality through income or wealth taxes increases economic inefficiency, but the overall picture is more complicated than in the competitive case.

\subsection{Endogenous Corporate Social Responsibility, Inequality, and Foreign Ownership}

In the model described above, corporate social responsibility arises as an endogenous objective of the firm. Friedman (1970) argued that the only valid objective of the firm is to maximize profits. This is not the case when firms have market power, since the Fisher Separation Theorem does not apply. Since the owners of the firms are part of society, for example as consumers, they will in general want firms to pursue objectives different from profit maximization.

This does not imply that the equilibrium level of corporate social responsibility will be the socially optimal one. In the model described in this section, the socially optimal firm policies are obtained in equilibrium when the wealth distribution is completely egalitarian. In this case, the result is Pareto optimal. Inequality in this case generates inefficiency because 
the owners of the firms want the latter to use its market power more aggressively to extract monopoly (or oligopoly) rents.

In general, the optimal level of corporate social responsibility will be an equilibrium when ownership is distributed in proportion to how affected each individual in society is by the policies of the oligopolistic firms. In the quasilinear model, because consumption of the oligopolistic good is the same for everyone, optimality is achieved when ownership is egalitarian. This differs, for example, from the results in Renstrom and Yalcin (2003), because in their model (a) preferences are homothetic, and (b) labor income is heterogeneous.

In a model with environmental externalities, these would be internalized to the extent that the owners are affected by them. The optimal level of pollution would be obtained if ownership is proportional to the damage generated by the firms to each member of society, with more affected members having a proportionally larger stake in the firms.

Another interesting implication of the theory is that, to the extent that foreigners do not consume the home country's goods, foreign ownership leads to less corporate social responsibility in equilibrium. This is consistent with the evidence provided by Blonigen and O'Fallon (2011), who show that foreign firms are less likely to donate to local charities.

\subsection{Solving for the Equilibrium with Incomplete Diversification}

Although we have assumed that in case of indifference agents choose diversified portfolios, it is possible to construct equilibria in which agents choose imperfectly diversified portfolios when they are indifferent. In this subsection, I show how the equilibrium varies for different levels of diversification and wealth inequality. For imperfectly diversified cases, we need to solve the system of equations defined by equation 10. Rearranging the terms, we obtain

$$
\sum_{s=1}^{N}\left\{\left[\int_{g \in G} \beta \theta_{n}^{g}\left(\theta_{n}^{g}+\theta_{s}^{g}-1\right) d g\right] q_{s}\right\}=\int_{g \in G}\left(\theta_{n}^{g}\right)^{2}(\alpha-m) d g \text { for } n=1, \ldots, N .
$$

This is a linear system, and the coefficients can be calculated by Monte Carlo integration. To do so, we need to specify a wealth distribution. I will use a lognormal wealth distribution, although the model can be solved easily for any distribution that can be sampled from.

Figure 5 shows the equilibrium quantity for different values of the $\sigma$ parameter of the wealth distribution and different values of the diversification parameter $\phi$, defined in the same way as in section 5 . The parameters of the oligopolistic industry are $\alpha=\beta=1$ and 
$m=0$. The number of firms is set to 3 , although it is not difficult to solve for the equilibrium with more firms. The Pareto efficient quantity for these values of the parameters is 1 . The classic Cournot quantity is 0.75 and the classic monopoly quantity is 0.5 . We can see that, when the distribution of wealth is completely egalitarian, the outcome is Pareto efficient independently of the portfolios. At all positive levels of wealth inequality, diversification reduces the equilibrium quantity. Also, for all levels of diversification, wealth inequality reduces the equilibrium quantity. We can also see that the collusive effect of diversification is greater at higher levels of wealth inequality. For values of $\sigma$ above 2 , at zero diversification the equilibrium quantity is approximately that of classic Cournot, which under the and with complete diversification it is approximately that of classic monopoly.

\subsection{Relaxing the Quasilinearity Assumption}

Suppose that preferences are not quasilinear. Then, the equilibrium under complete diversification is characterized by the solution to

$$
\max _{p} \int_{g \in G} \theta^{g} v\left(p, m^{g}(p)\right) d g
$$

where $v\left(p, m^{g}(p)\right)$ is the indirect utility function corresponding to the general utility function $U(x, y)$. Total income $m^{g}$ is the sum of labor income and profits:

$$
m^{g} \equiv w L+\theta^{g} \pi(p)
$$

The first order conditions are:

$$
\int_{g \in G} \theta^{g}\left[\frac{\partial v\left(p, m^{g}\right)}{\partial p}+\frac{\partial v\left(p, m^{g}\right)}{\partial m^{g}} \theta^{g} \frac{\partial \pi}{\partial p}\right] d g=0 .
$$

Using Roy's identity, we can rewrite this equation as

$$
\int_{g \in G} \theta^{g}\left[-x\left(p, m^{g}\right) \frac{\partial v\left(p, m^{g}\right)}{\partial m^{g}}+\frac{\partial v\left(p, m^{g}\right)}{\partial m^{g}} \theta^{g} \frac{\partial \pi}{\partial p}\right] d g=0 .
$$

If the wealth distribution is completely egalitarian, the solution is characterized by

$$
\frac{\partial \pi}{\partial p}-x(p, m)=0
$$


It is easy to check that this is the condition for Pareto optimality.

However, with general preferences an egalitarian distribution is not the only case under which the equilibrium is Pareto optimal. For example, if consumption of the oligopolistic good is proportional to ownership of the oligopolistic firms, then the result is also Pareto optimal. That is, the relevant condition is

$$
x\left(p, m^{g}\right)=\theta^{g} x(p) .
$$

Replacing this condition in the first order conditions, it is immediately clear that the solution is Pareto optimal. Note that, because there is labor income in addition to profit income, this condition does not correspond to homothetic preferences. While the condition is difficult to characterize in terms of the primitives of the model, the intuition is clear. The markup of the oligopolistic good affects agents in proportion to their consumption of that good. The optimal level of corporate social responsibility-in this case applied to the setting of markups-occurs in equilibrium when ownership is proportional to the level of consumption of the oligopolistic good.

\section{Empirical Evidence on Common Ownership and Mar- ket Power}

In this section, I discuss the results from an empirical analysis of the relationship between common ownership and market power. I start by showing the evolution of markups and measures of common ownership for a sample of US and Canadian firms over time. Second, I document a positive correlation between a company's markup and the fraction of firms in its industry with which it has common shareholders. To study the relationship in more depth, I show the results of structure-conduct-performance (SCP) regressions at the industry level, with average markups as the dependent variable and measures of common ownership, plus controls, as an explanatory variables. Finally, I study the joint dynamics of markups and common ownership measures using a Panel Vector Autoregression. The results are consistent with the hypothesis that common ownership acts as a partial form of integration. 


\subsection{Data}

I use two datasets: Compustat fundamentals quarterly North America for accounting data on American and Canadian firms, and Thomson Reuters institutional holdings for ownership data. I focus on the period 2000Q2-2010Q4. There are 180,355 firm-quarter observations that have data on both accounting and institutional ownership, with a total of 7277 firms. I drop from the sample industries that have only one firm in the data. After this, the sample has 179,201 firm-quarter observations. Then, I drop observations with earnings before taxes higher than revenues, observations with negative markups (the calculation of markups is explained in detail in the next paragraph), and observations with zero revenues. Thus, I end up with a sample size of 172,247 firm-quarter observations. The average number of firms in the sample per quarter is 4,006, with a minimum of 3,648 firms and a maximum of 4,267. There are 249 industries at the 3-digit SIC level represented in the sample. Because of the presence of extreme outliers, I windsorize the markup at the 1st and 99th percentiles.

The first step in the empirical analysis is to construct the adjacency matrix for a network of firms linked by the common ownership generated by institutional investors. I consider two firms as being connected in the shareholder network if there is at least one shareholder owning at least 5 percent in each firm. Once we have constructed this matrix, we can then calculate the degree of each firm at each point in time, that is, the number of connections with other firms in the network. We can also calculate the density of the network. The formula for the density of a network, given its adjacency matrix $Y$, is

$$
\text { Density }=\frac{\sum_{i=1}^{n} \sum_{j<i} y_{i j}}{n(n-1) / 2},
$$

where $n$ is the number of nodes in the network and $y_{i j}$ is equal to 1 if firm $i$ and firm $j$ are connected, and zero otherwise (by convention, a firm is not considered to be connected to itself, and thus the adjacency matrix has zeros in its diagonal).

In addition to a firm's overall degree, we will find it useful to consider its within-industry degree, that is, the number of connections that it has with other firms in the same industry. Because the number of firms in the sample varies across time, we will normalize both the overall degree and the within-industry degree by dividing them by the number of other firms in the sample, and the number of other firms in the sample that are in the same industry, respectively. These normalized measures represent the percentage of possible connections, 
rather than the raw number of connections.

We will also find it useful to consider, in addition to the density of the overall network, the density of the subnetwork for each industry. To do this, we take the firms in only one industry and consider the network formed by those firms and their connections.

Figure 6 shows a plot of the network for a random sample of 400 companies in 2010Q4, representing roughly $10 \%$ of the companies in the network. There are several clusters generated by a few institutional investors which have ownership stakes of more than 5 percent in a large number of companies. The two largest clusters, in the center of the network plot, are generated by BlackRock and Fidelity. The firms with the highest numbers of connections are those that belong to both of these two large clusters.

To calculate markups, I use data on revenues and earnings before taxes. The difference between these two is a measure of total cost. Markups are then calculated as

$$
\text { Markup }_{i t}=\frac{\text { Revenue }_{i t}}{\text { Cost }_{i t}}
$$

As is well known, this measure of markups has several drawbacks. The first is that it uses average cost rather than marginal cost, and is thus a measure of the average markup, rather than the markup at the margin, which is the one that the theory refers to. Second, it fails to capture all of the user cost of capital, since, although it includes interest expenses, does not take into account the opportunity cost of equity capital. Its main advantage is that it is possible to calculate it using standard accounting data, which is readily available for a large number of firms. However, it is important to keep in mind that markups are measured with error.

Table 1 shows summary statistics for assets, markups, whether a firm has a large shareholder, the number of connections of the firms in the sample in the shareholder network, the normalized number of connections (that is, the number of connections divided by the number of other firms in the sample for that quarter), and the normalized number of connections with other firms in the same industry (that is, the number of connections with other firms in the industry divided by the number of other firms in the industry for that quarter).

Figure 7 shows the evolution over time of the density of the shareholder network for the economy as a whole, and of the average density of the industry sub-networks. The points for 2010Q1 and 2010Q2 have been interpolated, because the lack of BlackRock data for those quarters distorted the measures substantially. The graph illustrates two interesting facts. 
First, industry subnetworks are denser on average than the overall network. This means that the probability that two firms will have a common shareholder is higher if they are in the same industry. A difference-in-means test shows that the difference is statistically significant. Second, the density of shareholder networks, both at the industry level and overall, increased substantially between 2000 and 2010. Both the overall density and the average within-industry density have approximately tripled over that period.

To understand why the density of shareholder networks has increased so much, we need to study the ownership data in more detail. Let's start by ranking the funds according to the number of firms in which they hold at least a 5 percent ownership stake (that is, they are blockholders in those firms). Consider the top 5 ranked funds in terms of blockholdings. For each period, we can calculate the percentage of firms in which the top 5 funds were blockholders. Figure 8 shows that the percentage of firms having top 5 funds as blockholders trended upward between 2000 and 2010, going from 30\% in 2000Q2 to 48\% in 2010Q4. Among the largest 1000 firms in terms of assets, the percentage of firms having top 5 funds as blockholders increased from 36\% in 2000Q2 to $45 \%$ in $2010 \mathrm{Q} 4$.

How did an increase in blockholding by top funds from around 30\% to around $50 \%$ over the last decade lead to a triplication in network densities? Consider the following calculation. Table 2 shows the top 5 funds in terms of blockholdings for the last quarter of 2001, 2004, 2007 and 2010, together with the number of firms in which they had blockholdings. In 2001Q4, the fund with blockholdings in the most companies was Dimensional, with blockholdings in 535 companies. Thus, it generated $\frac{535 \times 534}{2}=142,845$ connections between firms according to our definition. In 2010, the top-ranked fund in terms of blockholdings was BlackRock, with blockholdings in 1130 companies. Thus, at the end of 2010 BlackRock generated $\frac{1130 \times 1129}{2}=$ 637, 885 connections, more than four times the number of connections that Dimensional generated nine years ago, while the number of firms in the sample remained roughly constant. Figure 9 shows that the top 5 funds in terms of blockholdings generate the vast majority of the connections in the network. The percentage of connections generated by the top 5 institutions was $85 \%$ in 2000Q2, declined to $75 \%$ in 2007, and then increased to more than $90 \%$ in 2010 Q4.

Figure 10 shows the evolution of the average and median markups over time. Markups are procyclical, consistent with the evidence presented by Nekarda and Ramey (2010). There is also an upward trend, although it is slight compared to the large cyclical movements.

Figure 11 shows that there is a positive relationship between markups and firm size, 
measured as the logarithm of assets. I first average markups and log assets over time for each firm. Then, I divide the firms into deciles by size, and calculate the average markup for each decile. Interestingly, average markups are below one for the bottom 5 deciles, and above for the top 5. Figure 12 shows that smaller firms on average also have a higher fraction of periods with negative income (before taxes), and less periods with observations, presumably because of a higher probability of exit.

Figure 13 shows the result of a similar exercise, but dividing the firms by the number of within-industry connections instead of log assets. First, I separate the 2334 (out of 7277) firms that have no connections within their industry in any period, and calculate their average markup. Then, I divide the rest of the firms into quintiles according to the fraction of possible within-industry connections, and calculate the average markup for each group. There is a strong positive correlation between within-industry connections and markups. If we control for log assets, by using the residuals from a regression of markups on log assets (and adding the average markup to the residuals) instead of raw markups, the correlation in smaller, but still significant. Interestingly, there is a positive jump in markups when going from the second to the third quintile of connections. Figure 14 shows that more connected firms are on average less likely to have negative profits (before taxes). Figure 15 shows that more connected firms have more periods with observations, presumably because their exit probability is lower. In all cases, the relationships described hold when controlling for assets, with the exception that the fraction of periods with negative income is lower for firms with no connections than for connected firms in the lowest two quintiles.

\subsection{Regression Analysis}

Table 3 shows the results of structure-conduct-performance regressions of average industry markups on the density of industry common ownership subnetworks, average overall degree (normalized) of firms in the industry, and controls. The basic specification is

$$
\text { Markup }_{i t}=\beta_{0}+\beta_{1} \text { Density }_{i t}+\beta_{2} \text { Average Degree }_{i t}+\text { Controls }_{i t}+\epsilon_{i t} .
$$

Control variables include the average log of assets of the firms in the industry, the Herfindahl index, calculated using the share of revenues of the firms in the dataset, the number of firms in the industry (within the dataset), and the fraction of firms in the industry that have a large institutional shareholder, that is, an institutional investor owning more than 5 
percent of the firm.

The first specification is a cross-sectional regression for a balanced panel of 210 industries, using time averages of all variables. The second specification is estimated using a FamaMacBeth two-step procedure. The third specification uses the data without aggregating over time, and includes quarterly dummies to correct for temporal variation in markups. The fourth specification adds lagged markups, which helps control for omitted variable bias. The fifth specification includes industry fixed effects, which helps control for omitted variables that are constant over the whole period. The last specification includes both lagged markups and fixed effects. ${ }^{5}$

In all specifications, we see a positive relation between markups and within-industry shareholder density. We also see a negative relation between overall connectivity of firms in the industry (that is, including connections with firms in other industries) and markups. The partial correlation between within-industry density and markups is statistically significant in all specifications except the one with fixed effects but no lagged markups. Note that the lack of statistical significance in the case of fixed effects without lagged markups is driven by higher standard errors, rather than a lower coefficient. This suggests that a) some of the effect is coming from the between-industry variation, and b) some of the omitted variables are time-varying. Fixed effects estimates are known to exacerbate the bias due to measurement error. The measurement error problem could be substantial in this case, since a) we do not observe non-institutional owners, and b) using a 5\% threshold will count some firms as connected when they are not, and viceversa.

The positive relationship between average industry markups and within-industry shareholder network density is consistent with a partial horizontal integration interpretation. That is, industries where firms are more likely to share the same owners, according to the theory, should have higher markups all else equal. The negative relationship between average industry markups and average overall connectivity in terms of common ownership is consistent with a partial vertical integration interpretation. When firms become vertically integrated, the double marginalization problem is solved. Thus, standard industrial organization models predict that markups when firms are vertically integrated should be lower than when they are independent (see Tirole, 1994, chap. 4).

\footnotetext{
${ }^{5}$ While in general including both lagged dependent variables and fixed effects leads to inconsistent estimates, given the large number of periods (41 quarters) and the relatively low value of the autoregressive parameter, the bias in this case should be small.
} 
Industries with larger firms in terms of assets tend to have higher markups. Ownership concentration, measured as the fraction of firms in the industry with large shareholders (more than $5 \%$ ownership) has a statistically significant effect only in two specifications. In the Fama-MacBeth regression, the effect is positive and significant at $5 \%$. In the specification with fixed effects and lagged markups, the effect is negative and significant at $10 \%$. The Herfindahl index has no statistically significant effect, except for a negative effect, significant at $10 \%$, in the specification with fixed effects and lagged markups. The inverse of the number of firms in the industry does not have a statistically significant effect on markups. The lack of a clear relationship between measures of concentration and markups should not be too surprising, given the failure of the structure-conduct-performance literature to find a strong relationship between these measures of concentration and market power.

\subsection{Panel Vector Autoregression Analysis}

Table 4 shows the results of a one-lag panel vector autoregression, with quarterly dummies and without fixed effects. We see that markups do not help to explain the density of shareholder networks. Shareholder network density, on the other hand, has a positive and highly significant effect on markups. Consistent with the results from the regression analysis, average degree has a statistically significant negative effect. This is confirmed by the impulse response analysis, shown in Figures 16 and 17.

Table 5 shows the results of a one-lag panel vector autoregression, with quarterly dummies and fixed effects. The results are qualitatively similar as in the analysis without fixed effects. The effect of common ownership measures on markups is smaller, but still statistically significant. The impulse response posterior densities are shown in Figures 18 and 19.

\section{Conclusion}

In this paper, I have studied the effects of portfolio diversification on equilibrium outcomes in oligopolistic industries, both theoretically and empirically. From a theoretical point of view, the main contribution is the development of a model of oligopoly with shareholder voting. Instead of assuming that firms maximize profits, the objectives of the firms are derived by aggregating the objectives of their owners through majority voting. I have applied this model 
to classical partial equilibrium oligopoly and to general equilibrium models with oligopolistic firms. Portfolio diversification increases common ownership, and thus works as a partial form of integration among firms. In general equilibrium, oligopolistic firms take into account objectives of their owners that are not related to profits. For example, the shareholders internalize some of the effects that firm policies generate on them as consumers.

The theory developed in this paper has potentially important normative implications. For example, economists usually consider diversification, maximization of value for the shareholders by CEOs and managers, and competition to be desirable objectives. Within the context of the model developed in this paper, it is impossible to completely attain the three. If investors hold diversified portfolios and managers maximize shareholder value, then it follows that the outcome is collusive. It should be possible in principle to attain any two of the three objectives, or to partially attain each of them. This trilemma poses interesting questions for welfare analysis, since it is not clear how these three objectives should be weighted against each other. For example, how much diversification should we be willing to give up in order to reduce collusion? Should we prioritize maximization of shareholder value over reducing market power or increasing diversification? These issues are beyond the scope of this paper, and would thus be a natural direction for further research.

Market power in an industry is usually assessed by using concentration ratios or the Herfindahl index. This can be misleading if one does not, in addition, study the extent of common ownership in the industry. This applies to both horizontally and vertically related firms. Common ownership may act as a partial form of integration between firms. Antitrust policy has thus far focused on mergers and acquisitions. It may be useful to pay more attention to the partial integration that can be achieved through portfolio diversification.

The general equilibrium model also has implications that may be of interest from a normative point of view. Corporate social responsibility arises in equilibrium as an endogenous objective of the firm. Owners of oligopolistic firms will in general want their firms to pursue objectives beyond profit maximization. Socially optimal outcomes are achieved when the distribution of ownership is proportional to how affected the agents are by the policies of the oligopolistic firms. When consumption of oligopolistic goods increases less than proportionally with wealth, an increase in wealth inequality increases inefficiency. Another implication of the theory is that foreign ownership leads to less corporate social responsibility in equilibrium, which is consistent with evidence that shows that foreign-owned firms are less likely to donate to local charities than locally owned firms. 
From an empirical point of view, this paper makes two main contributions. First, I have documented the extent of common ownership among US corporations generated by institutional shareholders. Common ownership, as measured by the density of the network of interlocking shareholdings, has roughly tripled during the last decade. Second, I have shown evidence that common ownership within an industry is correlated with higher average markups in that industry, and common ownership with firms outside a firm's industry is correlated with lower average markups in that industry. Using a panel vector autoregression, I show that the timing goes from common ownership to average markups, and not the other way around. The evidence is thus consistent with a partial integration interpretation, where common ownership within the industry generates horizontal integration, and common ownership outside the industry generates vertical integration, and thus a reduction in double marginalization.

In this paper I have not modeled agency problems explicitly. Because diversification, all else equal, implies more dispersed ownership, it may increase managerial power relative to the shareholders. The potentially interesting interactions between diversification and agency are also a natural avenue for further research. 


\section{References}

Acemoglu, D., An Introduction to Modern Economic Growth, Princeton University Press, 2009 .

Agrawal, A. and G.N. Mandelker, "Large shareholders and the monitoring of managers: The case of antitakeover charter amendments," Journal of Financial and Quantitative Analysis, 1990, 25 (02), 143-161.

Ahn, D.S. and S. Oliveros, "Combinatorial Voting," 2010.

Alesina, A. and H. Rosenthal, Partisan politics, divided government, and the economy, Cambridge Univ Pr, 1995.

_ and _, "A theory of divided government," Econometrica: Journal of the Econometric Society, 1996, 64 (6), 1311-1341.

Arrow, K.J., "A difficulty in the concept of social welfare," The Journal of Political Economy, 1950, 58 (4), 328-346.

_, Collected papers of Kenneth J. Arrow: Social choice and justice, Belknap Pr, 1983.

Becht, M. and J.B. DeLong, "Why Has There Been So Little Block Holding in America?," 2005.

Berle, A.A. and G.C. Means, "The modern corporation and private property," 1940.

Bertrand, M. and S. Mullainathan, "Are CEOS Rewarded for Luck? The Ones without Principals Are*," Quarterly Journal of Economics, 2001, 116 (3), 901-932.

Bethel, J.E., J.P. Liebeskind, and T. Opler, "Block share purchases and corporate performance," The Journal of Finance, 1998, 53 (2), 605-634.

Blonigen, B. and C. O'Fallon, "Foreign Firms and Local Communities," Technical Report, National Bureau of Economic Research 2011.

Brander, J.A. and T.R. Lewis, "Oligopoly and financial structure: The limited liability effect," The American Economic Review, 1986, 76 (5), 956-970. 
Cestone, G., "Corporate financing and product market competition: An overview," Giornale degli Economisti e Annali di Economia, 1999, 58 (2), 269-300.

Chari, V.V., L.E. Jones, and R. Marimon, "The economics of split-ticket voting in representative democracies," The American Economic Review, 1997, 87 (5), 957-976.

Coughlin, P.J., Probabilistic voting theory, Cambridge Univ Pr, 1992.

DeAngelo, H., "Competition and unanimity," The American Economic Review, 1981, 71 (1), 18-27.

DeLong, J.B., "Did J.P. Morgan's men add value," Inside the Business Enterprise, 1991, pp. 205-36.

DeMarzo, P.M., "Majority voting and corporate control: the rule of the dominant shareholder," The Review of Economic Studies, 1993, 60 (3), 713-734.

Diamond, P.A., "The role of a stock market in a general equilibrium model with technological uncertainty," The American Economic Review, 1967, 57 (4), 759-776.

Dierker, E., H. Dierker, and B. Grodal, "Nonexistence of constrained efficient equilibria when markets are incomplete," Econometrica, 2002, 70 (3), 1245-1251.

Dixit, A., "A model of duopoly suggesting a theory of entry barriers," The Bell Journal of Economics, 1979, 10 (1), 20-32.

Dreze, J.H., "(Uncertainty and) the firm in general equilibrium theory," The Economic Journal, 1985, 95, 1-20.

Duffie, D. and W. Shafer, "Equilibrium and the Role of the Firm in Incomplete Markets, Research Paper no. 915, Graduate School of Business," 1986.

Ekern, S. and R. Wilson, "On the Theory of the Firm in an Economy with Incomplete Markets," Bell Journal of Economics, 1974, 5 (1), 171-180.

Fershtman, C. and K.L. Judd, "Equilibrium incentives in oligopoly," The American Economic Review, 1987, 77 (5), 927-940.

Foellmi, R. and J. Zweimuller, "Inequality, market power, and product diversity," Economics Letters, 2004, 82 (1), 139-145. 
Friedman, M., "The social responsibility of business is to increase its profits," New York Times Magazine, 1970, pp. 122-126.

Gillan, S.L. and L.T. Starks, "The Evolution of Shareholder Activism in the United States*," Journal of Applied Corporate Finance, 2007, 19 (1), 55-73.

Gompers, P.A. and A. Metrick, "Institutional investors and equity prices*," Quarterly Journal of Economics, 2001, 116 (1), 229-259.

Grossman, S.J. and J.E. Stiglitz, "On value maximization and alternative objectives of the firm," Journal of Finance, 1977, pp. 389-402.

Häckner, J., "A Note on Price and Quantity Competition in Differentiated Oligopolies," Journal of Economic Theory, 2000, 93 (2), 233-239.

Hansen, R.G. and J.R. Lott, "Externalities and corporate objectives in a world with diversified shareholder/consumers," Journal of Financial and Quantitative Analysis, 1996, $31(1)$.

Hartzell, J.C. and L.T. Starks, "Institutional investors and executive compensation," The Journal of Finance, 2003, 58 (6), 2351-2374.

Jensen, M.C. and J.B. Long, "Corporate investment under uncertainty and Pareto optimality in the capital markets," The Bell Journal of Economics and Management Science, 1972, pp. 151-174.

Kang, J.K. and A. Shivdasani, "Firm performance, corporate governance, and top executive turnover in Japan," Journal of Financial Economics, 1995, 38 (1), 29-58.

Kaplan, S.N. and B.A. Minton, "Appointments of outsiders to Japanese boards: Determinants and implications for managers," Journal of Financial Economics, 1994, 36 (2), $225-258$.

Kelsey, D. and F. Milne, "The existence of equilibrium in incomplete markets and the objective function of the firm," Journal of Mathematical Economics, 1996, 25 (2), 229-245.

_ and _, "Imperfect competition and corporate governance," Journal of Public Economic Theory, 2008, 10 (6), 1115-1141. 
Ledvina, A.F. and R. Sircar, "Bertrand and Cournot competition under asymmetric costs: number of active firms in equilibrium," 2010.

Makowski, L., "Competition and unanimity revisited," The American Economic Review, 1983, 73 (3), 329-339.

Matvos, G. and M. Ostrovsky, "Cross-ownership, returns, and voting in mergers," Journal of Financial Economics, 2008, 89 (3), 391-403.

Milne, F., "Corporate Investment and Finance Theory in Competitive Equilibrium*," Economic Record, 1974, 50 (4), 511-533.

_, "The firm's objective function as a collective choice problem," Public Choice, 1981, 37 (3), 473-486.

Myles, G.D., Public economics, Cambridge Univ Pr, 1995.

Neary, J.P., "The road less travelled: Oligopoly and competition policy in general equilibrium," 2002.

_., "International trade in general oligopolistic equilibrium," University College Dublin, mimeo, 2009.

Nekarda, C.J. and V.A. Ramey, "The Cyclical Behavior of the Price-Cost Markup," University of California, San Diego (July), 2010.

Parker, P.M. and L.H. Röller, "Collusive conduct in duopolies: multimarket contact and cross-ownership in the mobile telephone industry," The RAND Journal of Economics, 1997, pp. 304-322.

Poitevin, M., "Collusion and the Banking Structure of a Duopoly," Canadian Journal of Economics, 1989, 22 (2), 263-277.

Radner, R., "A note on unanimity of stockholders' preferences among alternative production plans: a reformulation of the Ekern-Wilson model," The Bell Journal of Economics and Management Science, 1974, pp. 181-184.

Renstrom, T. and E. Yalcin, "Endogenous firm objectives.," Journal of public economic theory., 2003, 5 (1), 67-94. 
Reynolds, R. J. and B. R. Snapp, "The competitive effects of partial equity interests and joint ventures," International Journal of Industrial Organization, 1986, 4, 141-153.

Roe, M.J., Strong managers, weak owners: The political roots of American corporate finance, Princeton Univ Pr, 1996.

Schmalensee, R., "Inter-industry studies of structure and performance. Ch. 16 in R. Schmalensee and R. Willig (eds.): Handbook of Industrial Organization, Vol. 2," 1989.

Singh, N. and X. Vives, "Price and quantity competition in a differentiated duopoly," The RAND Journal of Economics, 1984, 15 (4), 546-554.

Tirole, J., The theory of industrial organization, MIT press, 1994. 


\begin{tabular}{lcccccc}
\hline & No. Obs. & Mean & Median & 90th Pct. & 10th Pct. & Std. Dev. \\
\cline { 2 - 8 } & 172247 & 6844.6 & 384.7 & 8279 & 24.5 & 53692.5 \\
Assets & 172247 & 1.04 & 1.05 & 1.35 & 0.59 & 0.41 \\
Markup & 172247 & 0.71 & 1.0 & 1.0 & 0.0 & 0.46 \\
Large shareholder & 172247 & 326.5 & 88 & 986 & 0 & 424.9 \\
$\begin{array}{l}\text { Degree (number of connexions) } \\
\begin{array}{l}\text { Percentage of possible connections } \\
\text { with other firms in the economy }\end{array}\end{array}$ & 172247 & $7.7 \%$ & $2.1 \%$ & $23.1 \%$ & $0.0 \%$ & 0.10 \\
$\begin{array}{l}\text { Percentage of possible connections } \\
\text { with other firms in the same industry }\end{array}$ & 172247 & $10.2 \%$ & $1.2 \%$ & $32.2 \%$ & $0.0 \%$ & 0.15 \\
\hline
\end{tabular}

Table 1

Summary Statistics

This table shows summary statistics for the variables used in the analysis of shareholder networks and markups. The data is quarterly, and goes from 2000Q2 to 2010Q4. Assets are in millions of dollars. The calculation of markups is described in section 7.1. The percentage of connections with other firms in the economy is the total number of connections for a given firm in a given period divided by the number of firms in that period minus one. The percentage of connections with other firms in the same industry is calculated as the number of connections with firms in the same 3-digit SIC industry for a given firm in a given period divided by the number of firms in that industry in that period minus one. Two firms are considered connected if there is at least one shareholder holding at least $5 \%$ in both firms. Large shareholder is an indicator variable, equal to one if a company has a shareholder with at least $5 \%$ of the shares and zero otherwise. Outliers are windsorized at the 1st and 99th percentile by quarter. 


\begin{tabular}{|c|c|c|c|c|}
\hline Ranking & 2001 & 2004 & 2007 & 2010 \\
\hline 1 & $\begin{array}{l}\text { Dimensional } \\
\quad(535)\end{array}$ & $\begin{array}{l}\text { Fidelity } \\
\quad(715)\end{array}$ & $\begin{array}{l}\text { Fidelity } \\
\quad(820)\end{array}$ & $\begin{array}{l}\text { BlackRock } \\
\quad(1130)\end{array}$ \\
\hline 2 & $\begin{array}{l}\text { Fidelity } \\
\quad(523)\end{array}$ & $\begin{array}{l}\text { Barclays } \\
\quad(465)\end{array}$ & $\begin{array}{l}\text { Barclays } \\
\quad(649)\end{array}$ & $\begin{array}{l}\text { Fidelity } \\
(744)\end{array}$ \\
\hline 3 & $\begin{array}{l}\text { Wellington } \\
\qquad(243)\end{array}$ & $\begin{array}{l}\text { Dimensional } \\
\quad(337)\end{array}$ & $\begin{array}{l}\text { Dimensional } \\
\qquad(449)\end{array}$ & $\begin{array}{l}\text { Dimensional } \\
\quad(396)\end{array}$ \\
\hline 4 & $\begin{array}{l}\text { Price T. Rowe } \\
\qquad(189)\end{array}$ & $\begin{array}{l}\text { Wellington } \\
\qquad(290)\end{array}$ & $\begin{array}{l}\text { Price T. Rowe } \\
\qquad(342)\end{array}$ & $\begin{array}{l}\text { Vanguard } \\
\quad(395)\end{array}$ \\
\hline 5 & $\begin{array}{l}\text { Capital Res. and Mgmt. } \\
\qquad(156)\end{array}$ & $\begin{array}{l}\text { Price T. Rowe } \\
\qquad(270)\end{array}$ & $\begin{array}{l}\text { Wellington } \\
\qquad(329)\end{array}$ & $\begin{array}{l}\text { Price T. Rowe } \\
\quad(351)\end{array}$ \\
\hline
\end{tabular}

Table 2

Top 5 Institutional Investors by Number of Blockholdings

This table shows the top 5 institutional investors in terms of the number of firms in which they held ownership stakes of at least 5\% (blockholdings), for the last quarter of 2001, 2004, 2007 and 2010. The numbers in parentheses below each institution's name indicate the number of blockholdings. 


\begin{tabular}{|c|c|c|c|c|c|c|}
\hline \multirow{3}{*}{ Density } & \multicolumn{6}{|c|}{ Dependent Variable: Average Markup } \\
\hline & (1) & (2) & (3) & $(4)$ & (5) & (6) \\
\hline & $\begin{array}{c}0.246^{* * *} \\
(0.0819)\end{array}$ & $\begin{array}{c}0.0641^{* * *} \\
(0.00756)\end{array}$ & $\begin{array}{c}0.0668^{* *} \\
(0.0277)\end{array}$ & $\begin{array}{c}0.0246^{* *} \\
(0.0107)\end{array}$ & $\begin{array}{c}0.0240 \\
(0.0155)\end{array}$ & $\begin{array}{c}0.0213^{* *} \\
(0.0107)\end{array}$ \\
\hline Average Degree & $\begin{array}{c}-1.210^{* * *} \\
(0.347)\end{array}$ & $\begin{array}{c}-0.430^{* * *} \\
(0.0559)\end{array}$ & $\begin{array}{c}-0.403^{* * *} \\
(0.124)\end{array}$ & $\begin{array}{c}-0.125^{* * *} \\
(0.0477)\end{array}$ & $\begin{array}{c}-0.206^{* *} \\
(0.0863)\end{array}$ & $\begin{array}{l}-0.142^{* *} \\
(0.0568)\end{array}$ \\
\hline Average Log Assets & $\begin{array}{c}0.0312^{\text {*** }} \\
(0.00561)\end{array}$ & $\begin{array}{c}0.0329^{* * *} \\
(0.00143)\end{array}$ & $\begin{array}{c}0.0325^{* * *} \\
(0.00458)\end{array}$ & $\begin{array}{c}0.0112^{* * *} \\
(0.00193)\end{array}$ & $\begin{array}{c}0.0455^{* * *} \\
(0.00926)\end{array}$ & $\begin{array}{c}0.0322^{* * *} \\
(0.00674)\end{array}$ \\
\hline 1 / (Number of Firms) & $\begin{array}{l}-0.0354 \\
(0.0811)\end{array}$ & $\begin{array}{c}-0.00669 \\
(0.0160)\end{array}$ & $\begin{array}{c}0.000470 \\
(0.0525)\end{array}$ & $\begin{array}{c}0.0104 \\
(0.0196)\end{array}$ & $\begin{array}{c}0.120 \\
(0.111)\end{array}$ & $\begin{array}{c}0.124 \\
(0.0802)\end{array}$ \\
\hline Herfindahl & $\begin{array}{c}0.0489 \\
(0.0493)\end{array}$ & $\begin{array}{c}0.00725 \\
(0.00800)\end{array}$ & $\begin{array}{l}0.00365 \\
(0.0353)\end{array}$ & $\begin{array}{c}-0.00634 \\
(0.0129)\end{array}$ & $\begin{array}{l}-0.0739 \\
(0.0519)\end{array}$ & $\begin{array}{c}-0.0671^{*} \\
(0.0398)\end{array}$ \\
\hline Fraction w/Large Shareholders & $\begin{array}{c}0.0943 \\
(0.0631)\end{array}$ & $\begin{array}{c}0.0176^{* *} \\
(0.00837)\end{array}$ & $\begin{array}{c}0.0153 \\
(0.0248)\end{array}$ & $\begin{array}{c}0.00240 \\
(0.0107)\end{array}$ & $\begin{array}{c}-0.0221 \\
(0.0180)\end{array}$ & $\begin{array}{c}-0.0232^{*} \\
(0.0138)\end{array}$ \\
\hline Markup $_{t-1}$ & & & & $\begin{array}{c}0.679 * * * \\
(0.0314)\end{array}$ & & $\begin{array}{c}0.403^{* * *} \\
(0.0293)\end{array}$ \\
\hline Constant & $\begin{array}{c}0.855^{* * *} \\
(0.0640)\end{array}$ & $\begin{array}{c}0.867^{* * *} \\
(0.0104)\end{array}$ & $\begin{array}{c}0.879^{* * *} \\
(0.0417)\end{array}$ & $\begin{array}{c}0.271^{* * *} \\
(0.0324)\end{array}$ & $\begin{array}{c}0.817^{* * *} \\
(0.0519)\end{array}$ & $\begin{array}{c}0.452^{* * *} \\
(0.0439)\end{array}$ \\
\hline Quarterly Dummies & $\mathrm{N} / \mathrm{A}$ & $\mathrm{N} / \mathrm{A}$ & Yes & Yes & Yes & Yes \\
\hline Industry Fixed Effects & $\mathrm{N} / \mathrm{A}$ & $\mathrm{N} / \mathrm{A}$ & & & Yes & Yes \\
\hline Observations & 210 & 9,524 & 9,524 & 9,008 & 9,524 & 9,008 \\
\hline Number of Industries & 210 & 249 & 249 & 246 & 249 & 246 \\
\hline R-squared & 0.196 & 0.129 & 0.141 & 0.544 & 0.122 & 0.275 \\
\hline
\end{tabular}

Table 3

Average Markups and Measures of Common Ownership

This table shows industry-level regression results with average industry markups (before taxes) as the dependent variable and measures of common ownership as explanatory variables. Standard errors are in parentheses. Specification (1) is a cross-sectional regression of averages over time using a balanced panel, with White heteroskedasticity-robust standard errors. Specification (2) is estimated using the two-step procedure of Fama-MacBeth. The standard errors in specifications (3) to (6) are clustered at the industry level. $* * * \mathrm{p}<0.01, * * \mathrm{p}<0.05,{ }^{*} \mathrm{p}<0.1$. 


\begin{tabular}{|c|c|c|c|c|c|c|}
\hline & $\begin{array}{c}(1) \\
\text { Markup }\end{array}$ & $\begin{array}{c}(2) \\
\text { Density }\end{array}$ & $\begin{array}{c}(3) \\
\text { Degree }\end{array}$ & $\begin{array}{c}(4) \\
\text { Log Assets }\end{array}$ & $\begin{array}{c}(5) \\
\text { Herfindahl }\end{array}$ & $\begin{array}{c}(6) \\
\text { Large Sh. }\end{array}$ \\
\hline $\operatorname{Markup}_{t-1}$ & $\begin{array}{l}0.685^{* * *} \\
(0.00770)\end{array}$ & $\begin{array}{l}0.000689 \\
(0.00723)\end{array}$ & $\begin{array}{l}-0.00255 \\
(0.00165)\end{array}$ & $\begin{array}{c}-0.0391^{*} \\
(0.0233)\end{array}$ & $\begin{array}{c}0.00726 \\
(0.00568)\end{array}$ & $\begin{array}{c}0.0159^{*} \\
(0.00861)\end{array}$ \\
\hline Density $_{t-1}$ & $\begin{array}{c}0.0267^{* * *} \\
(0.00826)\end{array}$ & $\begin{array}{l}0.798^{* * *} \\
(0.00776)\end{array}$ & $\begin{array}{c}0.00143 \\
(0.00177)\end{array}$ & $\begin{array}{c}0.0402 \\
(0.0250)\end{array}$ & $\begin{array}{c}0.00195 \\
(0.00609)\end{array}$ & $\begin{array}{c}0.00684 \\
(0.00924)\end{array}$ \\
\hline Degree $_{t-1}$ & $\begin{array}{c}-0.155^{* * *} \\
(0.0346)\end{array}$ & $\begin{array}{c}0.240^{* * *} \\
(0.0325)\end{array}$ & $\begin{array}{l}0.903^{* * *} \\
(0.00740)\end{array}$ & $\begin{array}{l}-0.175^{*} \\
(0.105)\end{array}$ & $\begin{array}{r}-0.00837 \\
(0.0255)\end{array}$ & $\begin{array}{c}0.240^{* * *} \\
(0.0387)\end{array}$ \\
\hline Log Assets $_{t-1}$ & $\begin{array}{c}0.00843^{* * *} \\
(0.000832)\end{array}$ & $\begin{array}{c}-6.69 \mathrm{e}-05 \\
(0.000781)\end{array}$ & $\begin{array}{c}-0.000107 \\
(0.000178)\end{array}$ & $\begin{array}{l}0.976^{* * *} \\
(0.00252)\end{array}$ & $\begin{array}{l}-0.000865 \\
(0.000613)\end{array}$ & $\begin{array}{c}-0.00109 \\
(0.000930)\end{array}$ \\
\hline Herfindahl $_{t-1}$ & $\begin{array}{c}0.00674 \\
(0.00458)\end{array}$ & $\begin{array}{c}-0.00957^{* *} \\
(0.00430)\end{array}$ & $\begin{array}{c}-0.00350^{* * *} \\
(0.000978)\end{array}$ & $\begin{array}{l}0.00319 \\
(0.0139)\end{array}$ & $\begin{array}{l}0.948^{* * *} \\
(0.00337)\end{array}$ & $\begin{array}{c}-0.0223^{* * *} \\
(0.00512)\end{array}$ \\
\hline Large Sh.t-1 & $\begin{array}{c}0.00456 \\
(0.00638)\end{array}$ & $\begin{array}{c}0.0145^{* *} \\
(0.00598)\end{array}$ & $\begin{array}{c}0.00390 * * * \\
(0.00136)\end{array}$ & $\begin{array}{c}-0.0664^{* * *} \\
(0.0193)\end{array}$ & $\begin{array}{c}-0.0172^{* * *} \\
(0.00470)\end{array}$ & $\begin{array}{l}0.798^{* * *} \\
(0.00713)\end{array}$ \\
\hline Constant & $\begin{array}{c}0.277^{* * *} \\
(0.0113)\end{array}$ & $\begin{array}{l}0.00150 \\
(0.0106)\end{array}$ & $\begin{array}{c}0.00758 * * * \\
(0.00241)\end{array}$ & $\begin{array}{c}0.203^{* * *} \\
(0.0342)\end{array}$ & $\begin{array}{l}0.0201^{* *} \\
(0.00832)\end{array}$ & $\begin{array}{c}0.127^{* * *} \\
(0.0126)\end{array}$ \\
\hline $\begin{array}{l}\text { Quarterly Dummies } \\
\text { Observations } \\
\text { R-squared }\end{array}$ & $\begin{array}{c}\text { Yes } \\
9,008 \\
0.540\end{array}$ & $\begin{array}{l}\text { Yes } \\
9,008 \\
0.705\end{array}$ & $\begin{array}{c}\text { Yes } \\
9,008 \\
0.835\end{array}$ & $\begin{array}{c}\text { Yes } \\
9,008 \\
0.951\end{array}$ & $\begin{array}{c}\text { Yes } \\
9,008 \\
0.899\end{array}$ & $\begin{array}{c}\text { Yes } \\
9,008 \\
0.704\end{array}$ \\
\hline
\end{tabular}

Table 4

Vector Autoregression Results

This table shows regression results for a vector autoregression with one lag, without industry fixed effects. Standard errors in parentheses. ${ }^{* * *} \mathrm{p}<0.01,{ }^{* *} \mathrm{p}<0.05,{ }^{*} \mathrm{p}<0.1$. 


\begin{tabular}{|c|c|c|c|c|c|c|}
\hline & $\begin{array}{c}(1) \\
\text { Markup }\end{array}$ & $\begin{array}{c}(2) \\
\text { Density }\end{array}$ & $\begin{array}{c}(3) \\
\text { Degree }\end{array}$ & $\begin{array}{c}(4) \\
\log \text { Assets }\end{array}$ & $\begin{array}{c}(5) \\
\text { Herfindahl }\end{array}$ & $\begin{array}{c}(6) \\
\text { Large Sh. }\end{array}$ \\
\hline $\operatorname{Markup}_{t-1}$ & $\begin{array}{l}0.416^{* * *} \\
(0.00979)\end{array}$ & $\begin{array}{c}-0.0144 \\
(0.00967)\end{array}$ & $\begin{array}{l}-0.00384^{*} \\
(0.00220)\end{array}$ & $\begin{array}{l}-0.0252 \\
(0.0302)\end{array}$ & $\begin{array}{l}0.000910 \\
(0.00705)\end{array}$ & $\begin{array}{l}0.00444 \\
(0.0112)\end{array}$ \\
\hline Density $_{t-1}$ & $\begin{array}{l}0.0217^{* *} \\
(0.00970)\end{array}$ & $\begin{array}{l}0.664^{* * *} \\
(0.00958)\end{array}$ & $\begin{array}{l}-0.00226 \\
(0.00218)\end{array}$ & $\begin{array}{c}0.0159 \\
(0.0299)\end{array}$ & $\begin{array}{l}-0.00179 \\
(0.00699)\end{array}$ & $\begin{array}{r}-0.00260 \\
(0.0111)\end{array}$ \\
\hline Degree $_{t-1}$ & $\begin{array}{c}-0.142^{* * *} \\
(0.0405)\end{array}$ & $\begin{array}{c}0.252^{* * *} \\
(0.0400)\end{array}$ & $\begin{array}{l}0.806^{* * *} \\
(0.00911)\end{array}$ & $\begin{array}{c}0.125 \\
(0.125)\end{array}$ & $\begin{array}{l}-0.0124 \\
(0.0292)\end{array}$ & $\begin{array}{l}0.105^{* *} \\
(0.0463)\end{array}$ \\
\hline $\log _{\text {Assets }_{t-1}}$ & $\begin{array}{c}0.0105^{* * * *} \\
(0.00259)\end{array}$ & $\begin{array}{c}0.00219 \\
(0.00255)\end{array}$ & $\begin{array}{c}0.00208 * * * \\
(0.000581)\end{array}$ & $\begin{array}{l}0.711^{* * *} \\
(0.00797)\end{array}$ & $\begin{array}{c}-0.00506^{* * *} \\
(0.00186)\end{array}$ & $\begin{array}{r}0.0135^{* * *} \\
(0.00296)\end{array}$ \\
\hline Herfindahl $_{t-1}$ & $\begin{array}{c}0.0242^{* *} \\
(0.0123)\end{array}$ & $\begin{array}{c}-0.0511^{* * *} \\
(0.0121)\end{array}$ & $\begin{array}{c}-0.0155^{* * *} \\
(0.00276)\end{array}$ & $\begin{array}{l}-0.0384 \\
(0.0378)\end{array}$ & $\begin{array}{l}0.568^{* * *} \\
(0.00884)\end{array}$ & $\begin{array}{c}-0.130^{* * *} \\
(0.0140)\end{array}$ \\
\hline Large Sh.t-1 & $\begin{array}{l}-0.00440 \\
(0.00814)\end{array}$ & $\begin{array}{c}-0.0127 \\
(0.00804)\end{array}$ & $\begin{array}{c}-0.00911^{* * *} \\
(0.00183)\end{array}$ & $\begin{array}{l}0.0450^{*} \\
(0.0251)\end{array}$ & $\begin{array}{c}-0.0342^{* * *} \\
(0.00587)\end{array}$ & $\begin{array}{l}0.592^{* * *} \\
(0.00931)\end{array}$ \\
\hline Constant & $\begin{array}{c}0.555^{* * *} \\
(0.0203)\end{array}$ & $\begin{array}{c}0.0657^{* * *} \\
(0.0201)\end{array}$ & $\begin{array}{c}0.0462^{* * *} \\
(0.00457)\end{array}$ & $\begin{array}{c}2.015^{* * *} \\
(0.0626)\end{array}$ & $\begin{array}{c}0.239^{* * *} \\
(0.0146)\end{array}$ & $\begin{array}{c}0.267^{* * * *} \\
(0.0232)\end{array}$ \\
\hline $\begin{array}{l}\text { Quarterly Dummies } \\
\text { Industry Fixed Effects } \\
\text { Observations } \\
\text { R-squared }\end{array}$ & $\begin{array}{c}\text { Yes } \\
\text { Yes } \\
9,008 \\
0.617\end{array}$ & $\begin{array}{c}\text { Yes } \\
\text { Yes } \\
9,008 \\
0.728\end{array}$ & $\begin{array}{c}\text { Yes } \\
\text { Yes } \\
9,008 \\
0.848\end{array}$ & $\begin{array}{c}\text { Yes } \\
\text { Yes } \\
9,008 \\
0.958\end{array}$ & $\begin{array}{c}\text { Yes } \\
\text { Yes } \\
9,008 \\
0.920\end{array}$ & $\begin{array}{c}\text { Yes } \\
\text { Yes } \\
9,008 \\
0.742\end{array}$ \\
\hline
\end{tabular}

Table 5

Vector Autoregression Results

This table shows regression results for a vector autoregression with one lag, with industry fixed effects. Standard errors in parentheses. $* * * \mathrm{p}<0.01, * * \mathrm{p}<0.05,{ }^{*} \mathrm{p}<0.1$. 


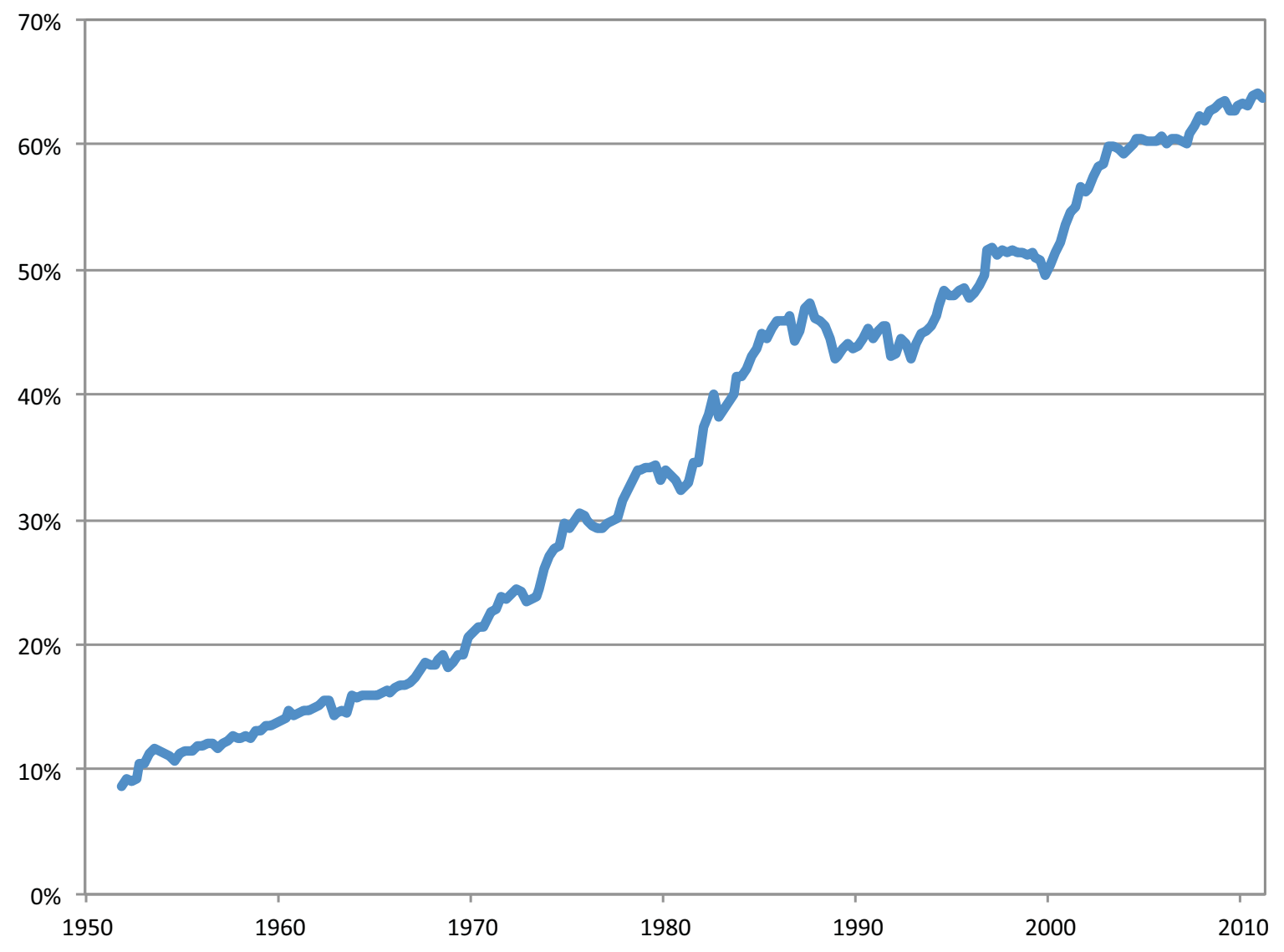

Figure 1

Percentage Ownership of Institutional Investors in U.S. Stock Markets

Source: Federal Reserve Flow of Funds. 

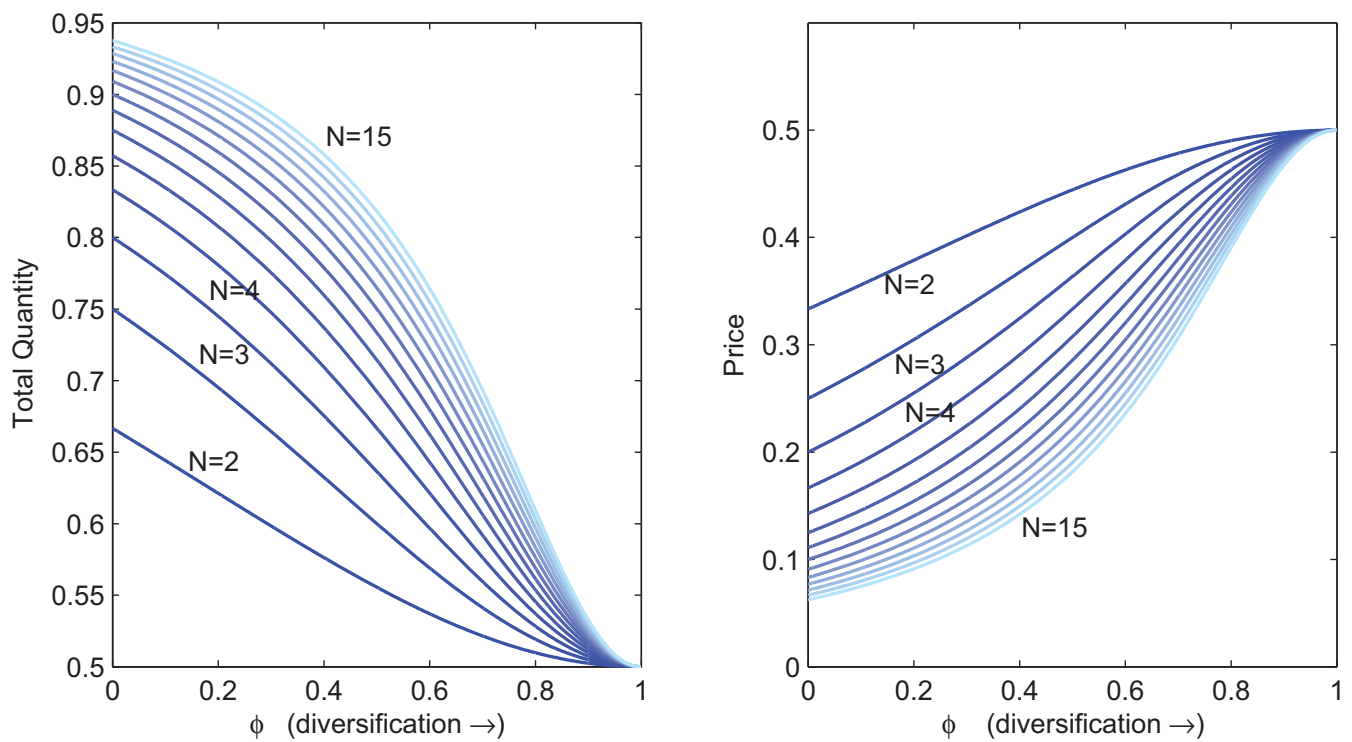

Figure 2

Equilibrium Quantities and Prices for Different Levels of Portfolio Diversification in a Cournot Oligopoly with Homogeneous Goods

The solution to the model is shown for $\alpha=\beta=1$, and $m=0$. For these parameter values, the competitive equilibrium quantity is 1 , and the collusive quantity is .5. The competitive price is zero, and the collusive price is .5 . 

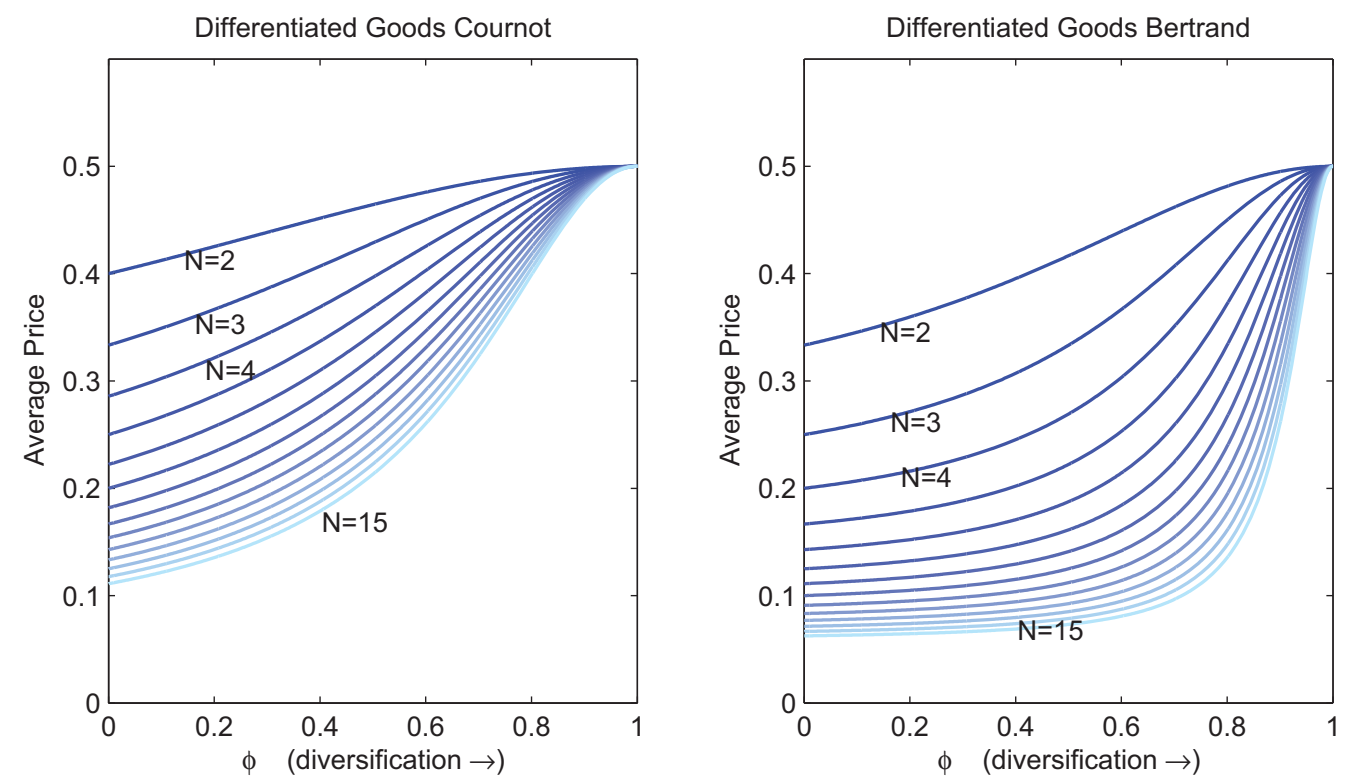

Figure 3

Equilibrium Prices for Different Levels of Portfolio Diversification in Cournot and Bertrand Oligopoly with Differentiated Goods

The solution to the model is shown for $\alpha=\beta=1$, and $m=0$. For these parameter values, the competitive equilibrium price is zero, and the collusive price is .5 . 


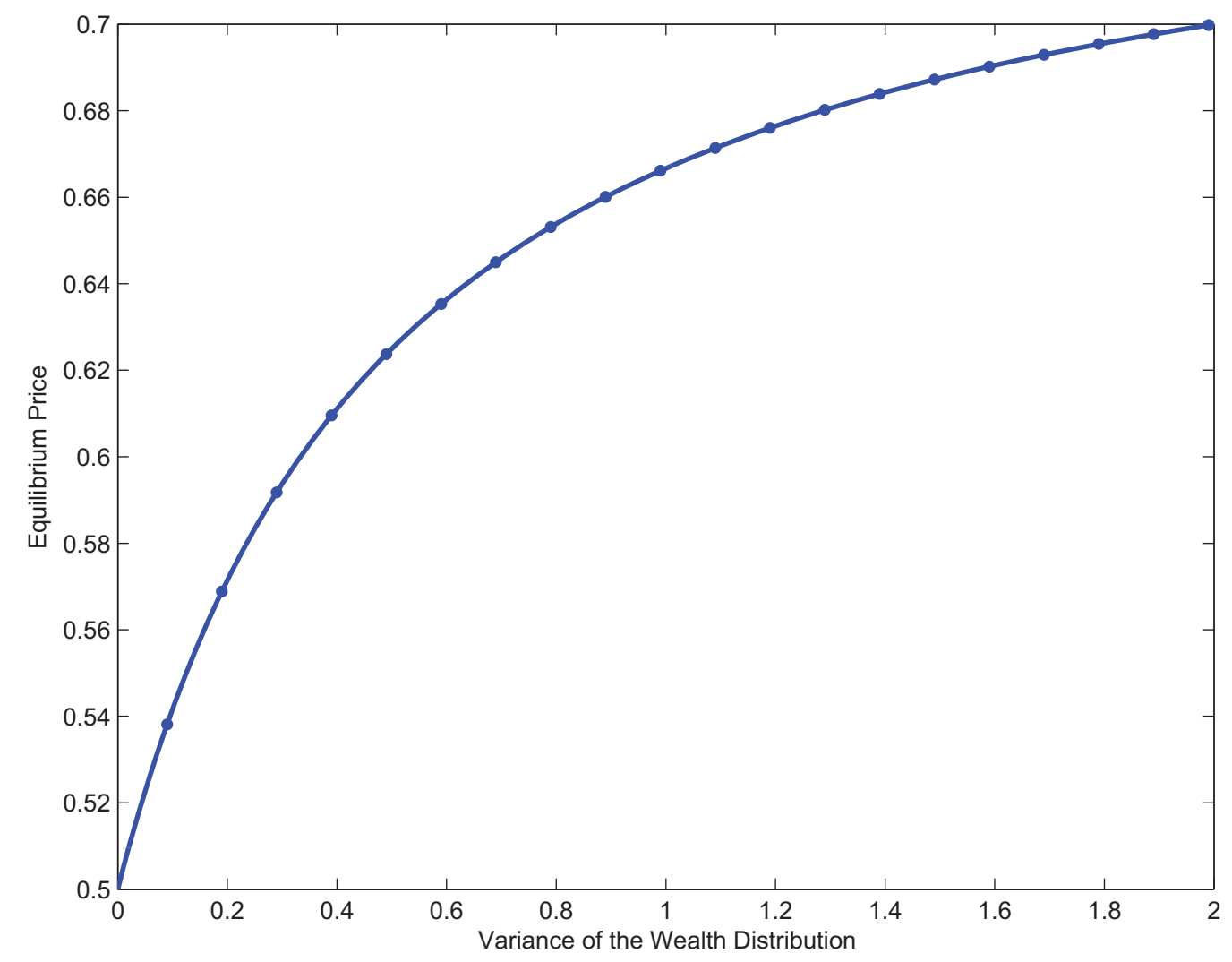

Figure 4

Equilibrium Prices in the Quasilinear General Equilibrium Model for Different Levels of Initial Wealth Inequality

The solution to the model is shown for $\alpha=\beta=1$ and $m=.5$. The number of firms does not affect the equilibrium price. For these parameter values, the price consistent with a Pareto optimal quantity of good $x$ is .5. The classic monopoly price is .75 . 


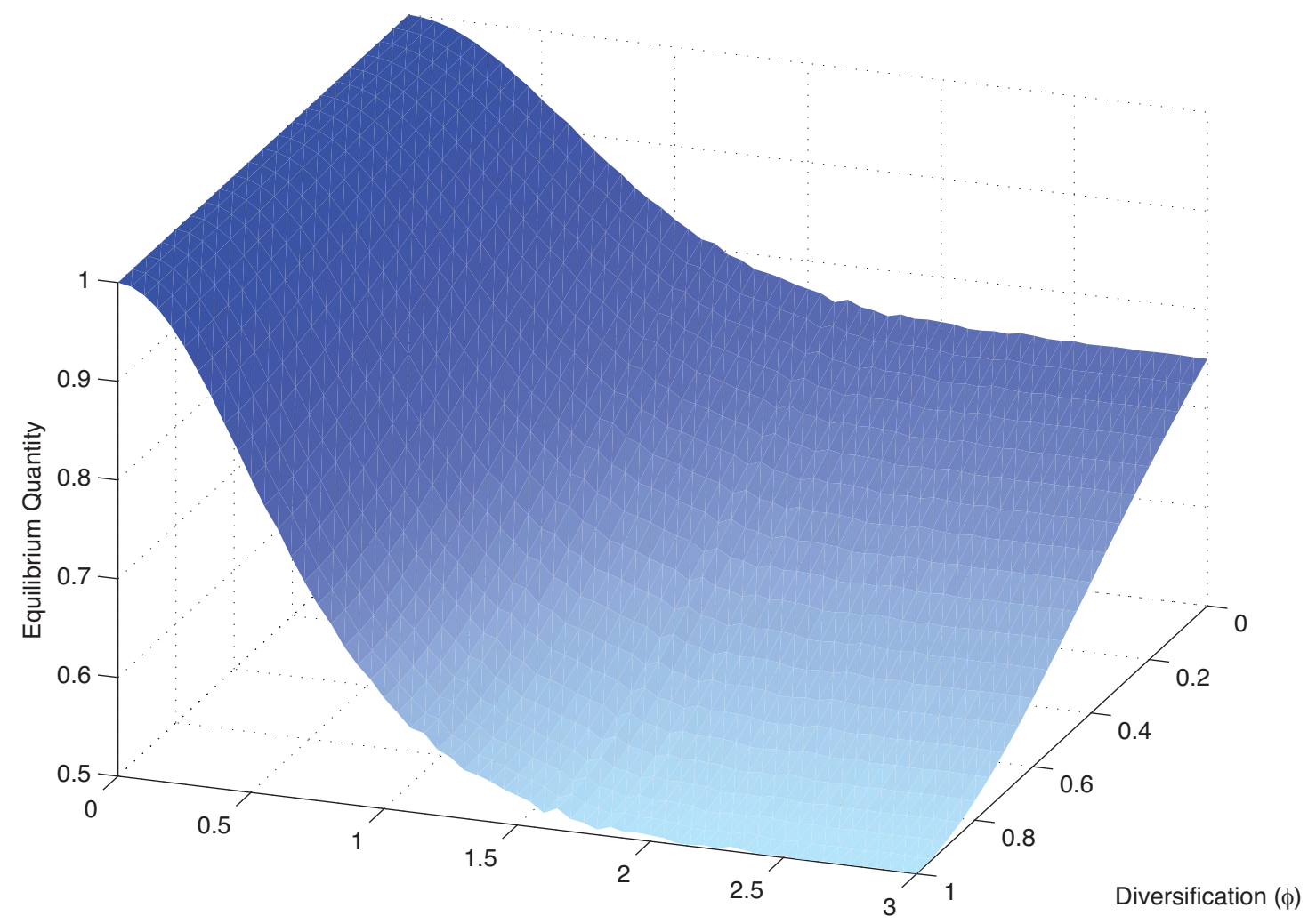

Wealth Inequality $(\sigma)$

Figure 5

Equilibrium Quantity of the Oligopolistic Good in the Quasilinear General Equilibrium Model for Different Levels of Wealth Inequality and Diversification (Lognormal Wealth Distribution)

The solution to the model is shown for $\alpha=\beta=1, m=.5$, and $N=3$. For these parameter values, the Pareto optimal quantity of good $x$ is 1 . The classic Cournot and classic monopoly quantities are .75 and .5, respectively. 


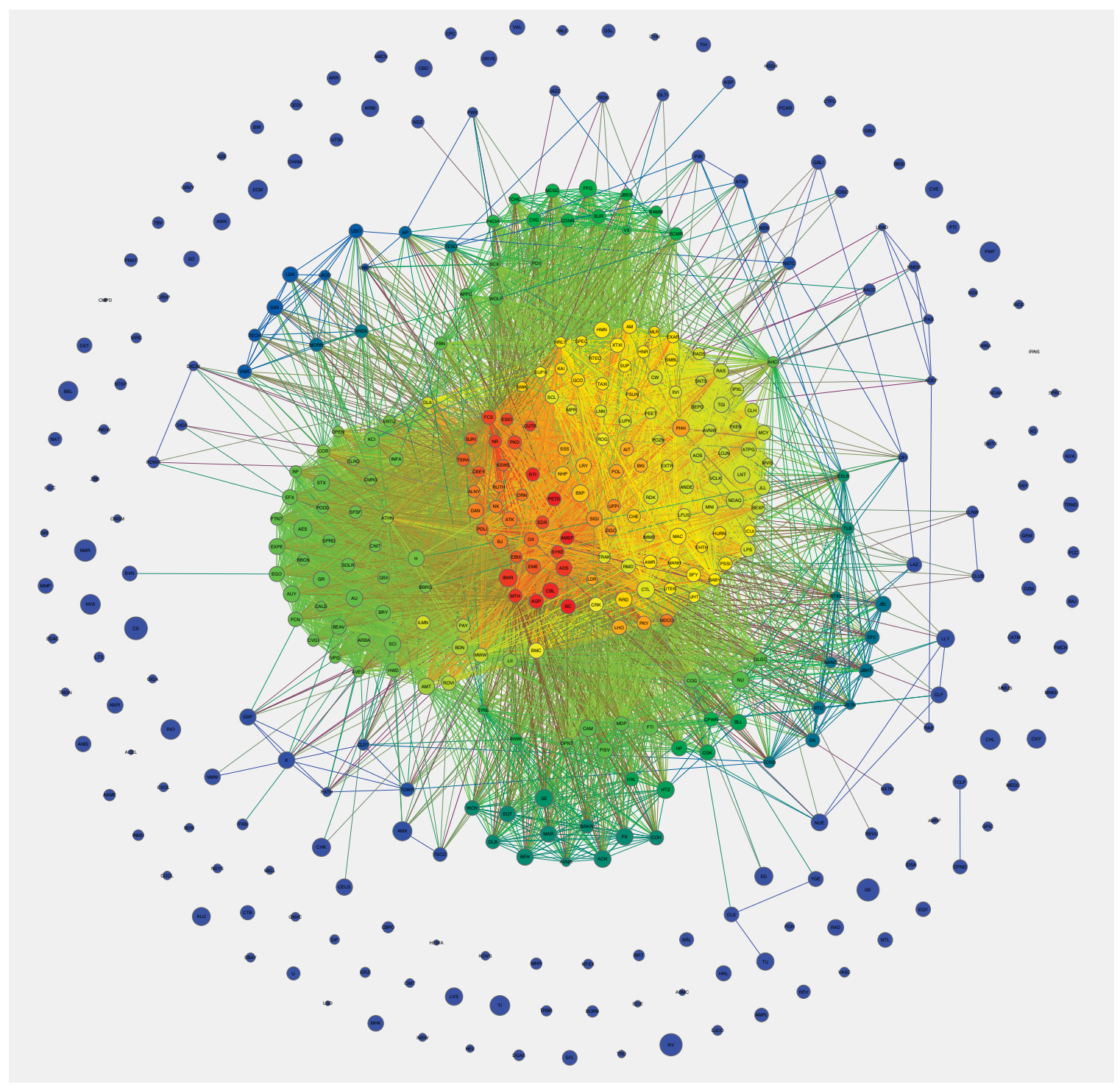

Figure 6

Shareholder Network (Random Sample of 400 Companies in 2010Q4)

This figure shows a plot of a random sample of 400 companies in the network of firms in 2010Q4. The edges are generated by common institutional shareholders with ownership stakes of at least $5 \%$ in a pair of firms. The layout of the network is calculated using a Fruchterman-Reingold algorithm. The size of the circles is proportional to the logarithm of a company's assets. The color represents the number of connections of the company, with colors closer to blue indicating less connections, and colors closer to red indicating more connections. 


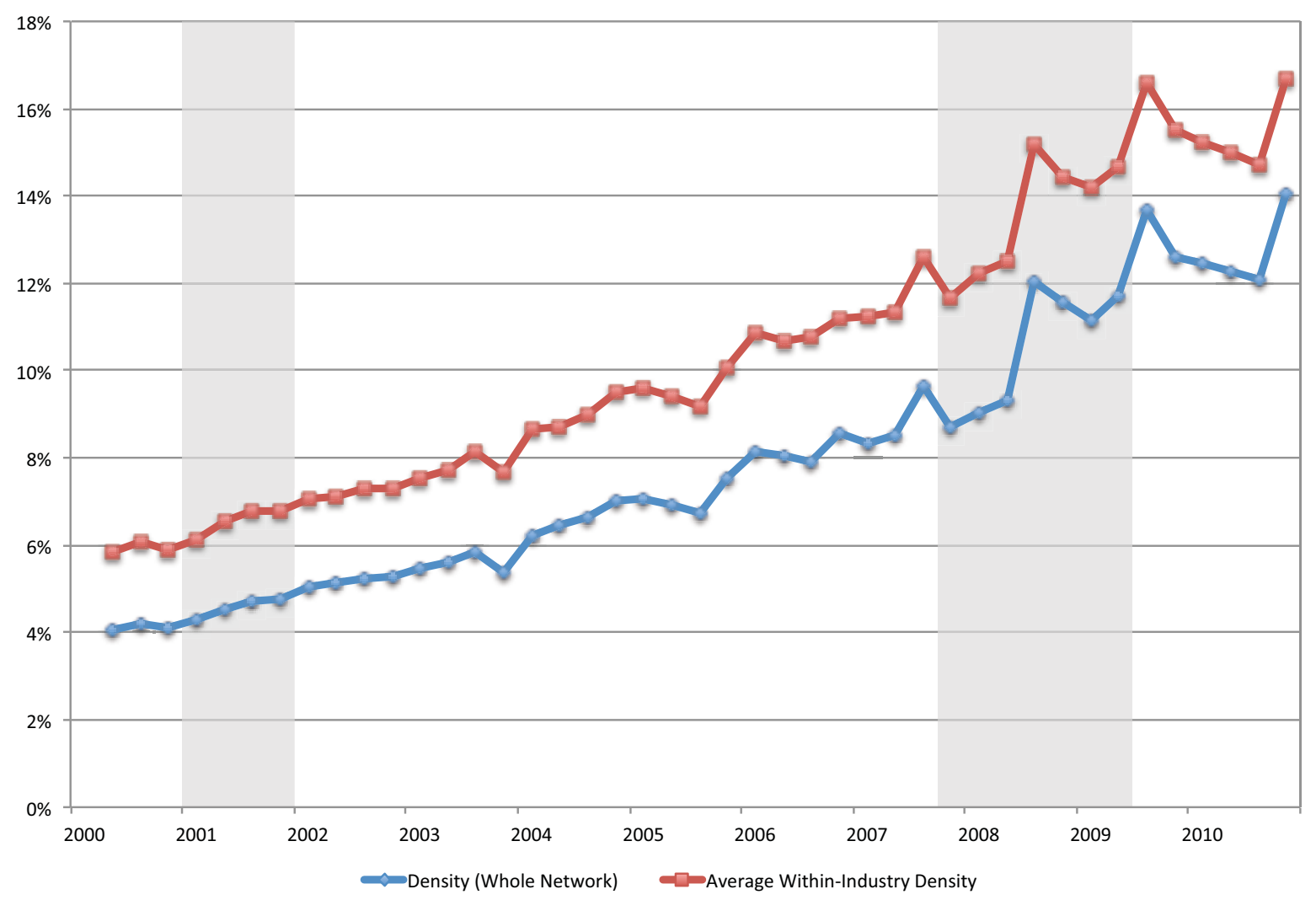

Figure 7

Shareholder Network Density over Time

This figure shows the evolution of the density of the network of firms generated by common institutional shareholders with ownership stakes of at least $5 \%$ in a pair of firms, and of the average density of the industry subnetworks. Industries are defined at the 3-digit SIC level. The values for 2010Q1 and 2010Q2 are interpolated (linearly) because ownership data for BlackRock, the top institution in terms of number of blockholdings in 2010, was not available for those quarters. 


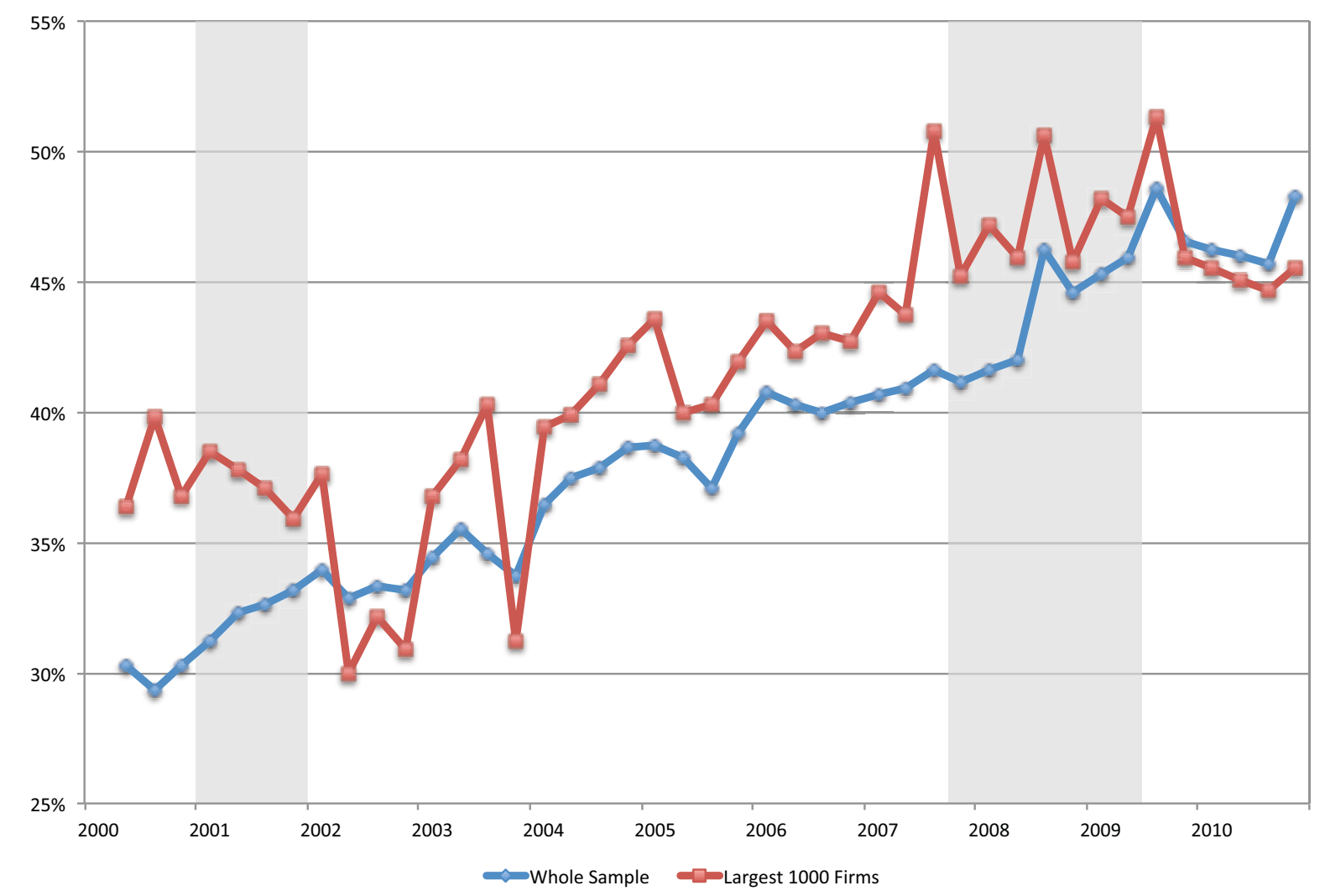

Figure 8

Percentage of Firms Having a Top 5 Fund as Blockholder (More than 5\% Ownership)

This figure shows the evolution over time of the percentage of firms that have a top 5 fund as a blockholder. A blockholder is defined as an investor with an ownership stake of at least $5 \%$ in a company. The top 5 funds are defined according to a ranking of funds based on the number of blockholdings. The ranking is updated every quarter. The values for 2010Q1 and 2010Q2 are interpolated (linearly) because ownership data for BlackRock, the top institution in terms of number of blockholdings in 2010, was not available for those quarters. 


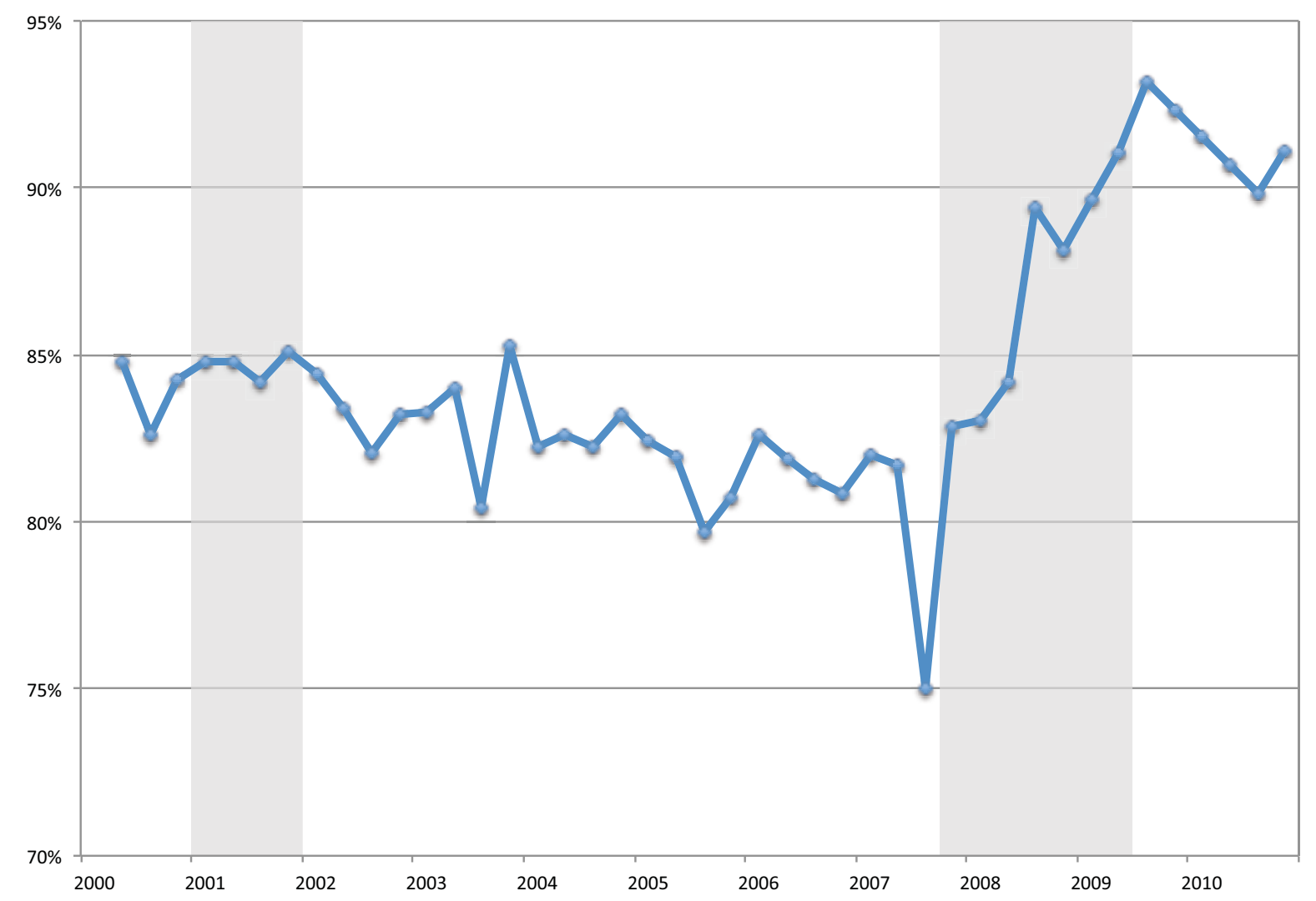

Figure 9

Percentage of Connections in the Network Generated by Top 5 Funds

This figure shows the evolution over time of the percentage of connections in the network generated bythe top 5 funds. This is calculated as the number of connections in a network with only the edges generated by the top 5 funds divided by the number of connections in the overall network. The top 5 funds are defined according to a ranking of funds based on the number of blockholdings. The ranking is updated every quarter. The ranking is updated every quarter. The values for 2010Q1 and 2010Q2 are interpolated (linearly) because ownership data for BlackRock, the top institution in terms of number of blockholdings in 2010, was not available for those quarters. 


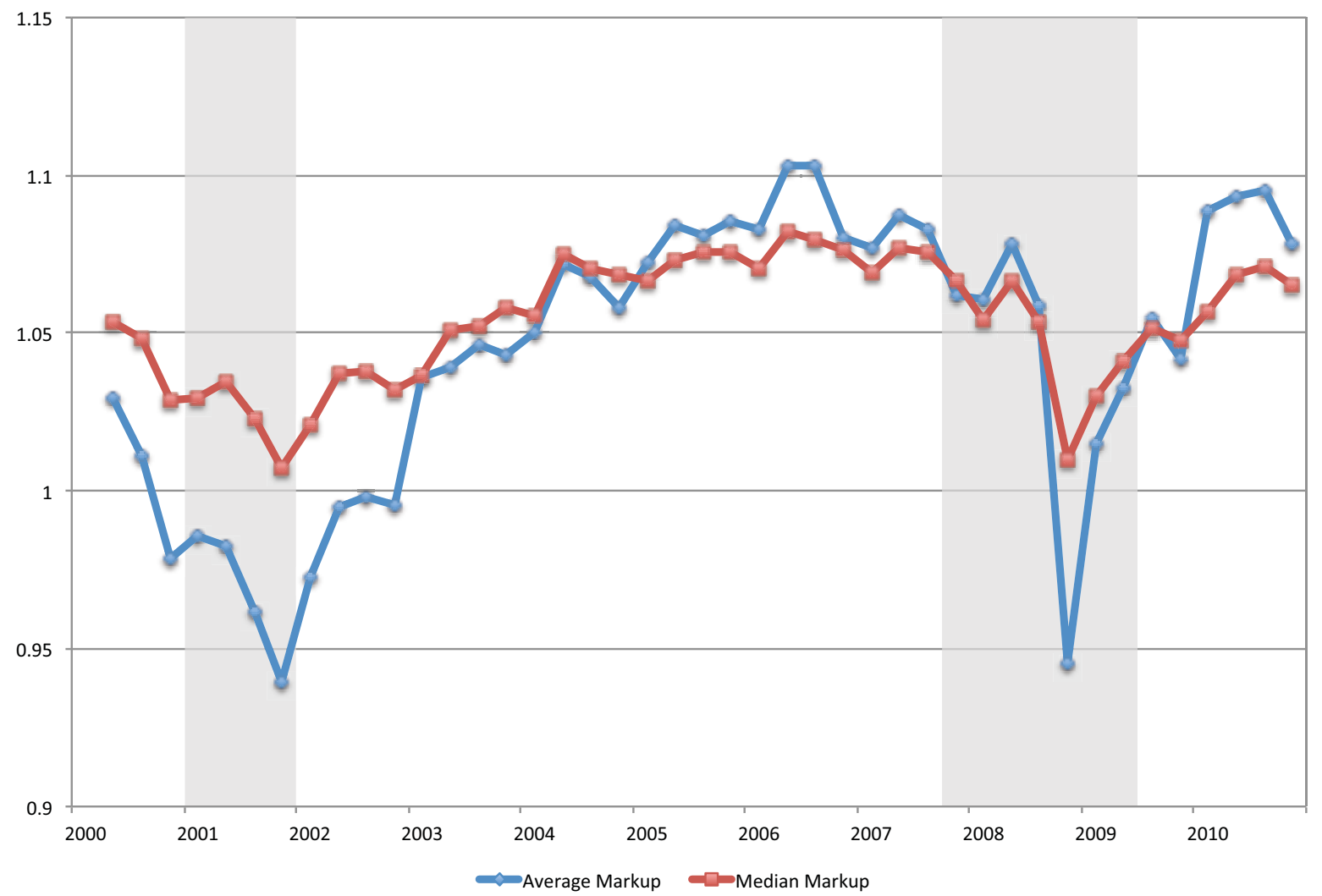

Figure 10

Average and Median Markups over Time

This figure shows the evolution over time of the average and median markup for the firms in the sample. Markups are calculated as total accounting revenues (before taxes) divided by total accounting costs (before taxes). 


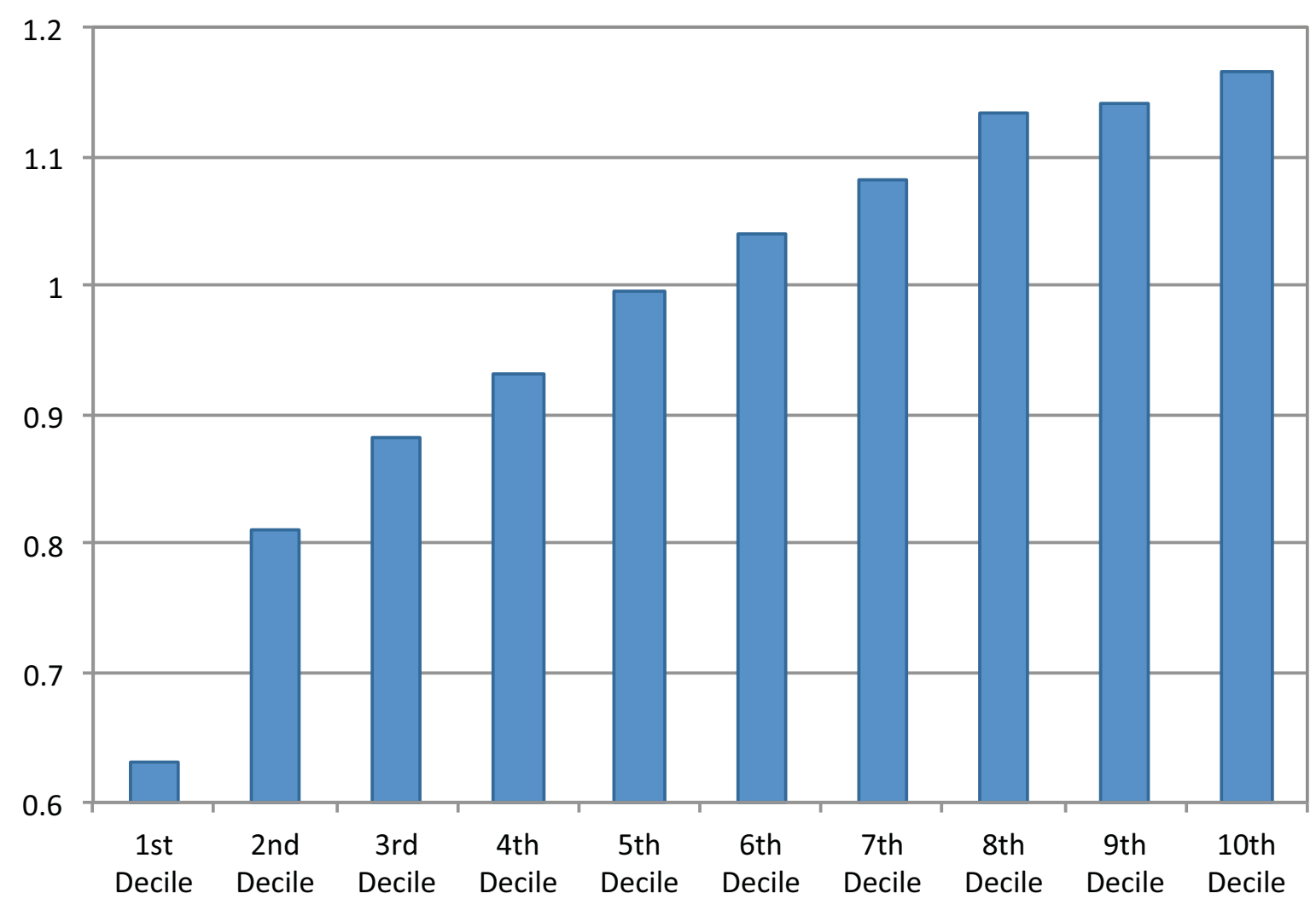

Figure 11

Average Markup, by Decile of Log Assets

This figure shows the average markup in the cross section of firms for each decile of firm size, measured as $\log$ assets. The markup of each firm and its log assets are averaged over all the periods for which it has observations. 


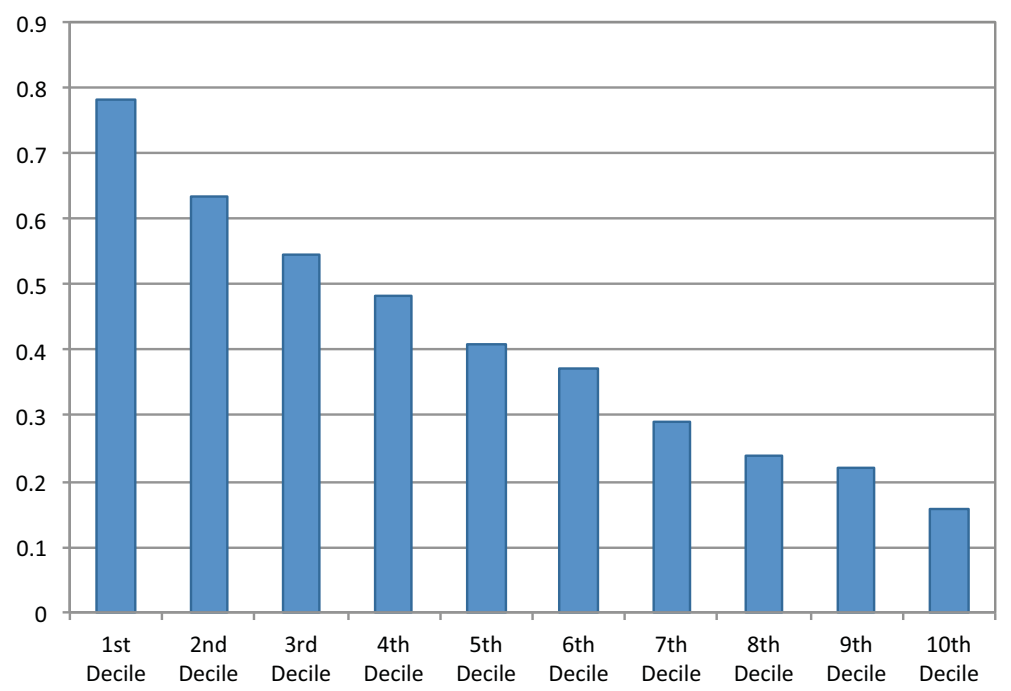

(a) Average Fraction of Periods with Negative Income (Before Taxes)

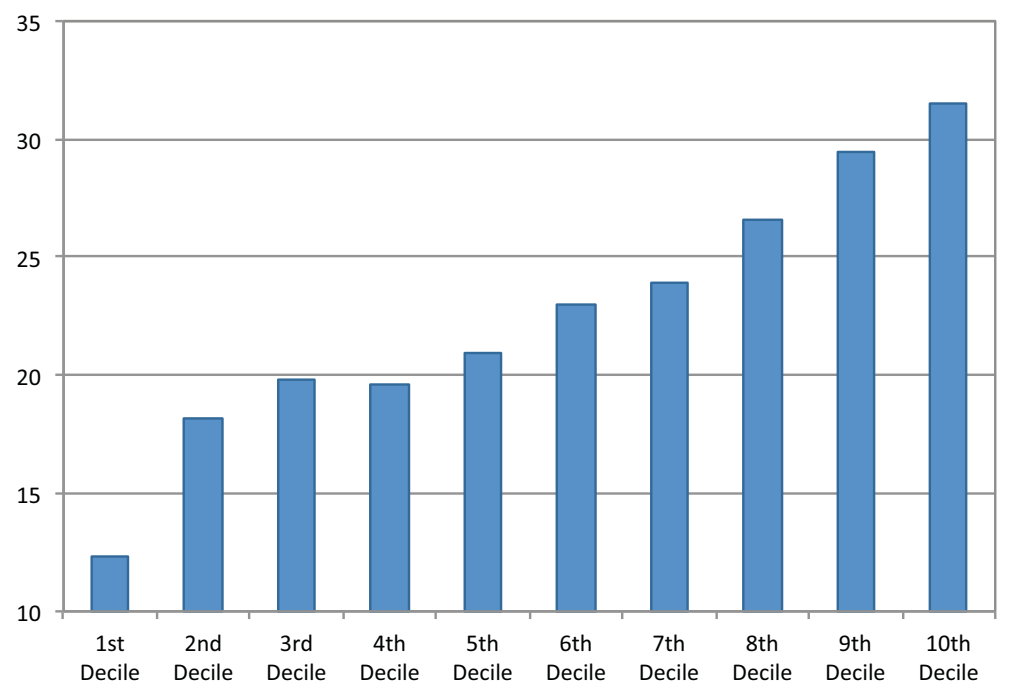

(b) Average Number of Periods with Observations

Figure 12

Average Fraction of Periods with Negative Income (Before Taxes) and Average Number of Periods with Observations, by Decile of Log Assets

This figure shows the average fraction of periods with negative income before taxes and the average fraction of periods for which a firm has observations, in the cross section of firms for each decile of firm size, measured as $\log$ assets. 


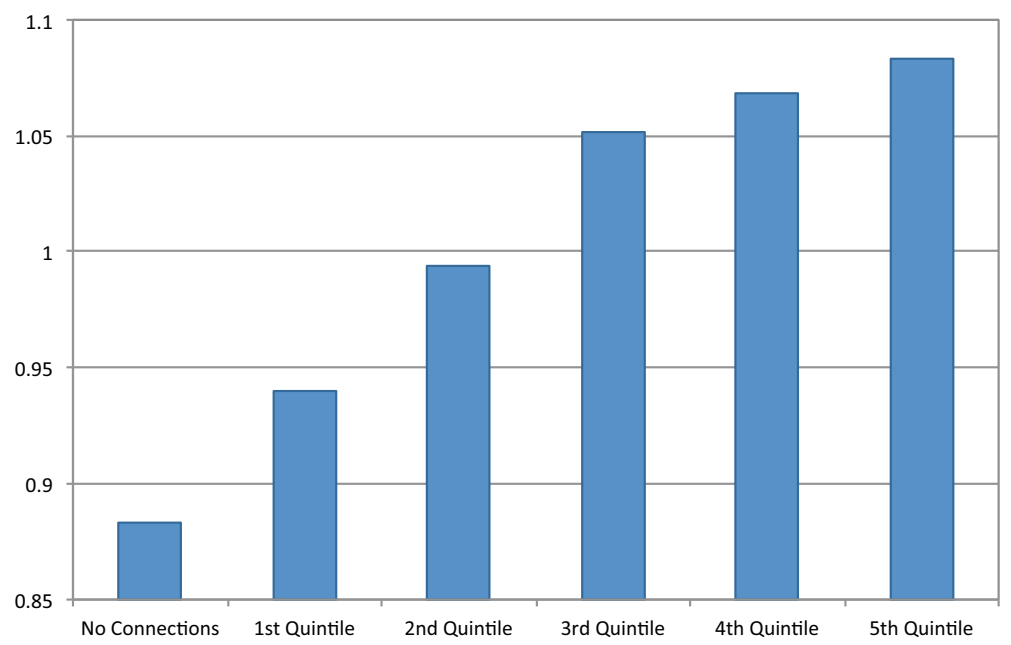

(a) No Controls

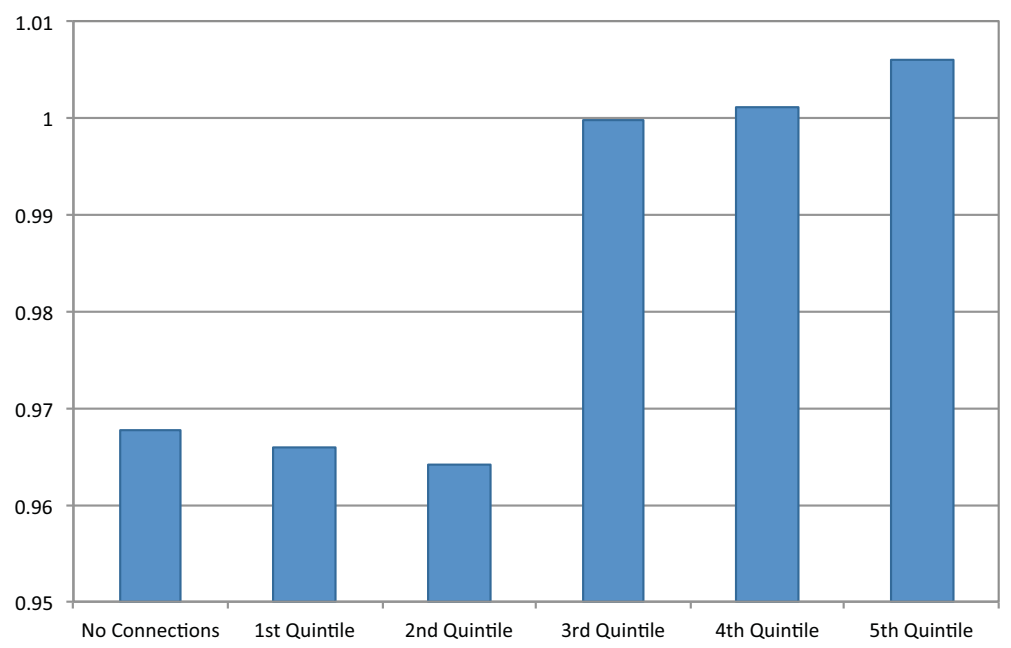

(b) Controlling for Log Assets

Figure 13

Average Markup, by Quintile of Within-Industry Degree

This figure shows the average markup in the cross section of firms for each quintile of within-industry normalized degree, after separating the observations with zero within-industry connections. Within-industry normalized degree is calculated as the number of connections that a company has with other firms in the same 3-digit SIC industry divided by the number of other firms in the industry (i.e. the number of possible connections). The markup of each firm and its log assets are averaged over all the periods for which it has observations. 


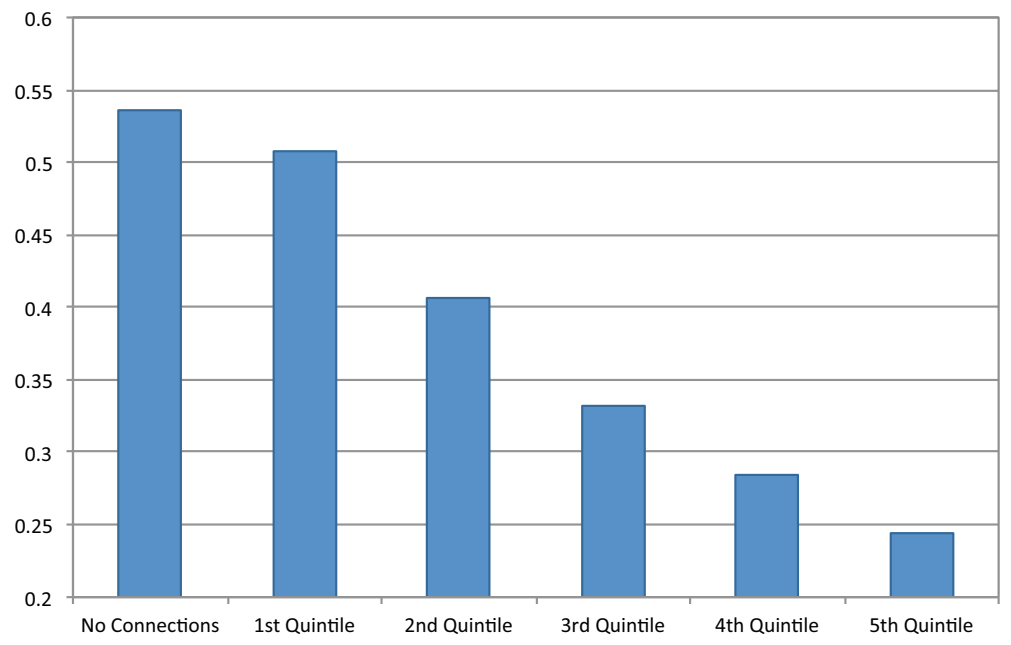

(a) No Controls

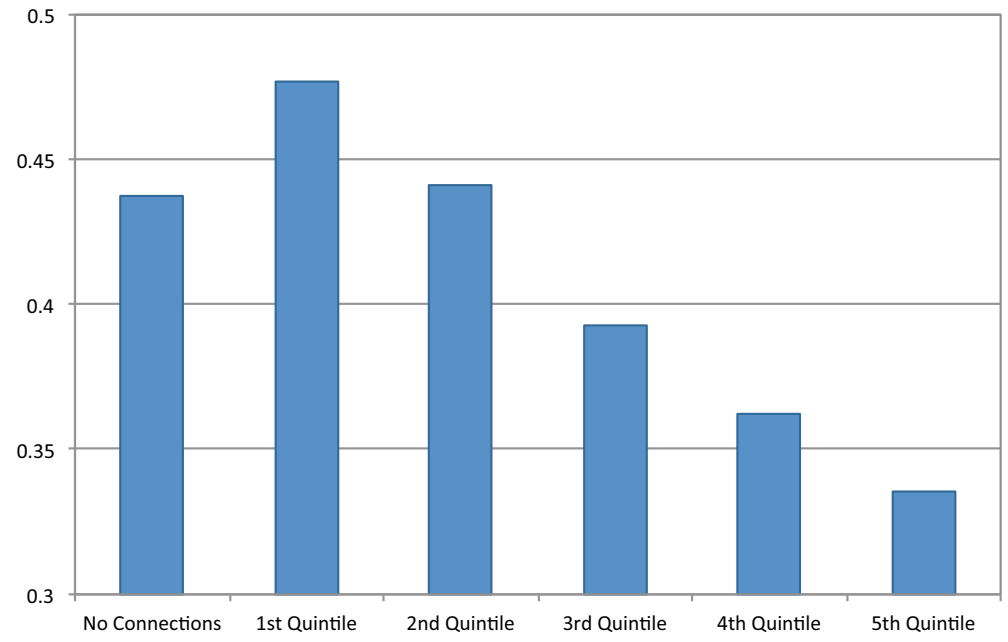

(b) Controlling for Log Assets

Figure 14

Average Fraction of Periods with Negative Income, by Quintile of Within-Industry Degree

This figure shows the average fraction of periods with negative income in the cross section of firms for each quintile of within-industry normalized degree, after separating the observations with zero within-industry connections. Within-industry normalized degree is calculated as the number of connections that a company has with other firms in the same 3-digit SIC industry divided by the number of other firms in the industry (i.e. the number of possible connections). 


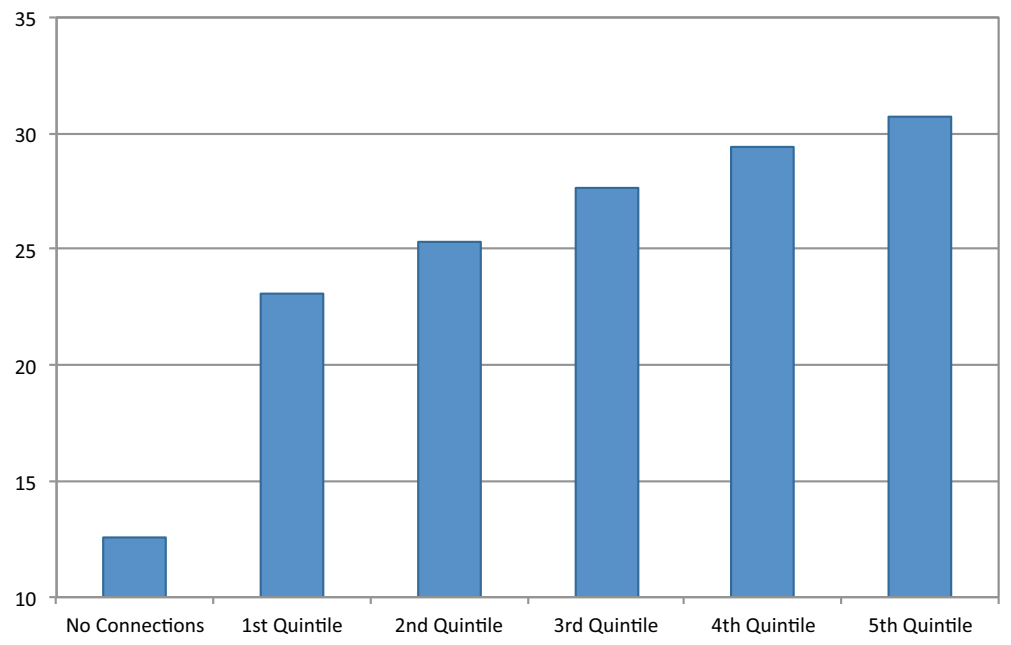

(a) No Controls

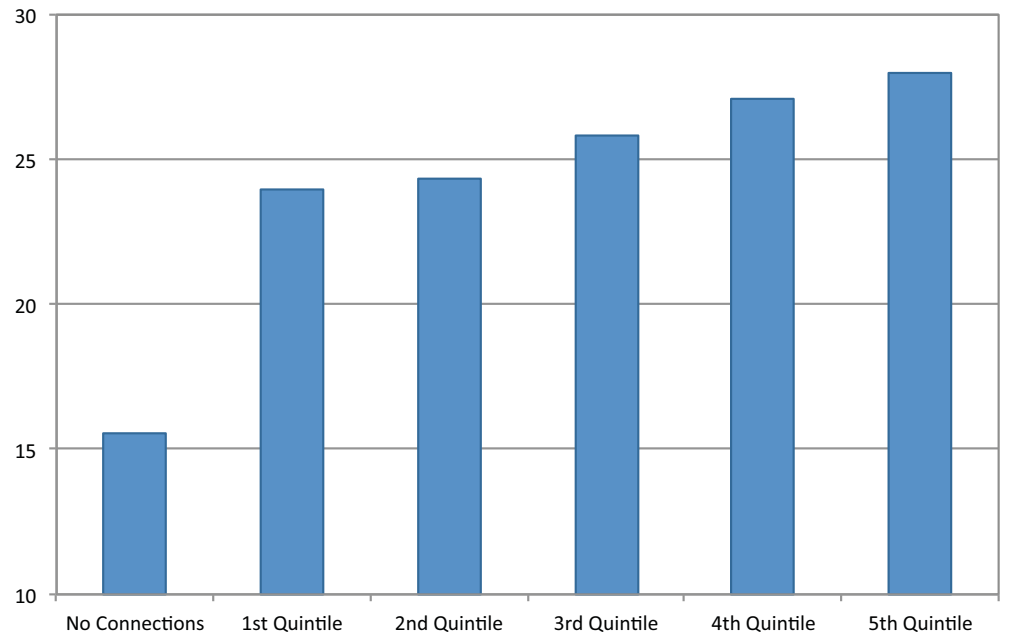

(b) Controlling for Log Assets

Figure 15

Average Number of Periods with Observations, by Quintile of Within-Industry Degree

This figure shows the average number of periods with observations in the cross section of firms for each quintile of within-industry normalized degree, after separating the observations with zero within-industry connections. Within-industry normalized degree is calculated as the number of connections that a company has with other firms in the same 3-digit SIC industry divided by the number of other firms in the industry (i.e. the number of possible connections). 

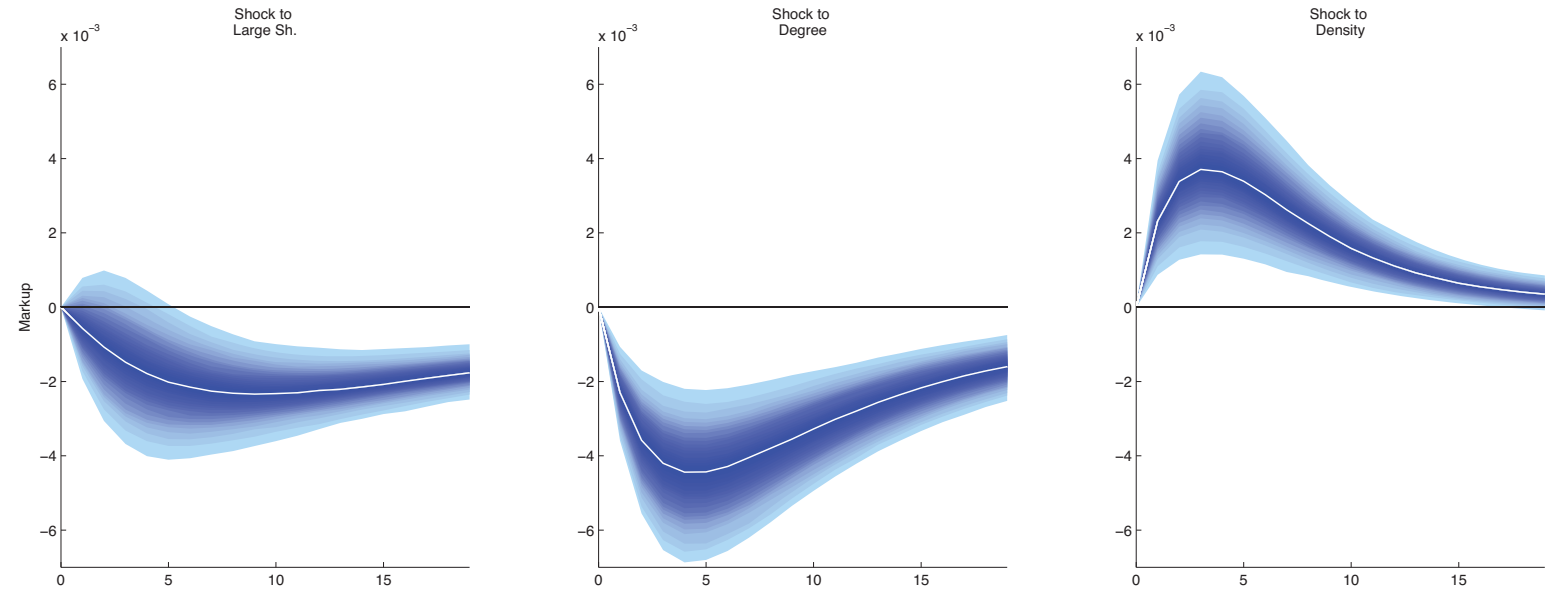

Figure 16

Response of the Average Industry Markup to Shocks to Ownership Structure Variables

This figure shows the posterior density, in a Panel VAR model, of the response of average markups to shocks to the fraction of firms with large shareholders in the industry, the average overall degree of the firms in the industry, and the industry's shareholder subnetwork density. The endogenous variables in the VAR are average log assets, the Herfindahl index, average markups, the fraction of firms with a large shareholder, the average degree, and the density of the industry network. Quarterly dummies are treated as exogenous variables. In each figure, the $\mathrm{x}$ axis indicates number of quarters after shock. The graph shows bands from $5 \%$, up to $95 \%$, in intervals of $5 \%$. 

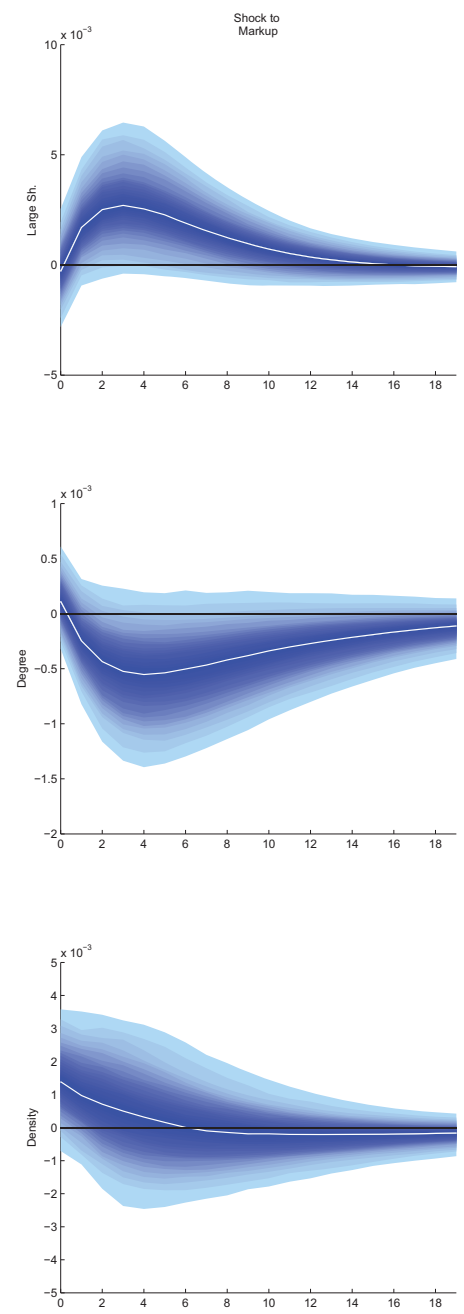

Figure 17

Response of Ownership Structure Variables to Shocks to Average Industry Markups

This figure shows the posterior density, in a Panel VAR model, of the response of the fraction of firms with large shareholders in the industry, the average overall degree of the firms in the industry, and the industry's shareholder subnetwork density to shocks to average markups. The endogenous variables in the VAR are average log assets, the Herfindahl index, average markups, the fraction of firms with a large shareholder, the average degree, and the density of the industry network. Quarterly dummies are treated as exogenous variables. In each figure, the $\mathrm{x}$ axis indicates number of quarters after shock. The graph shows bands from $5 \%$, up to $95 \%$, in intervals of $5 \%$. 

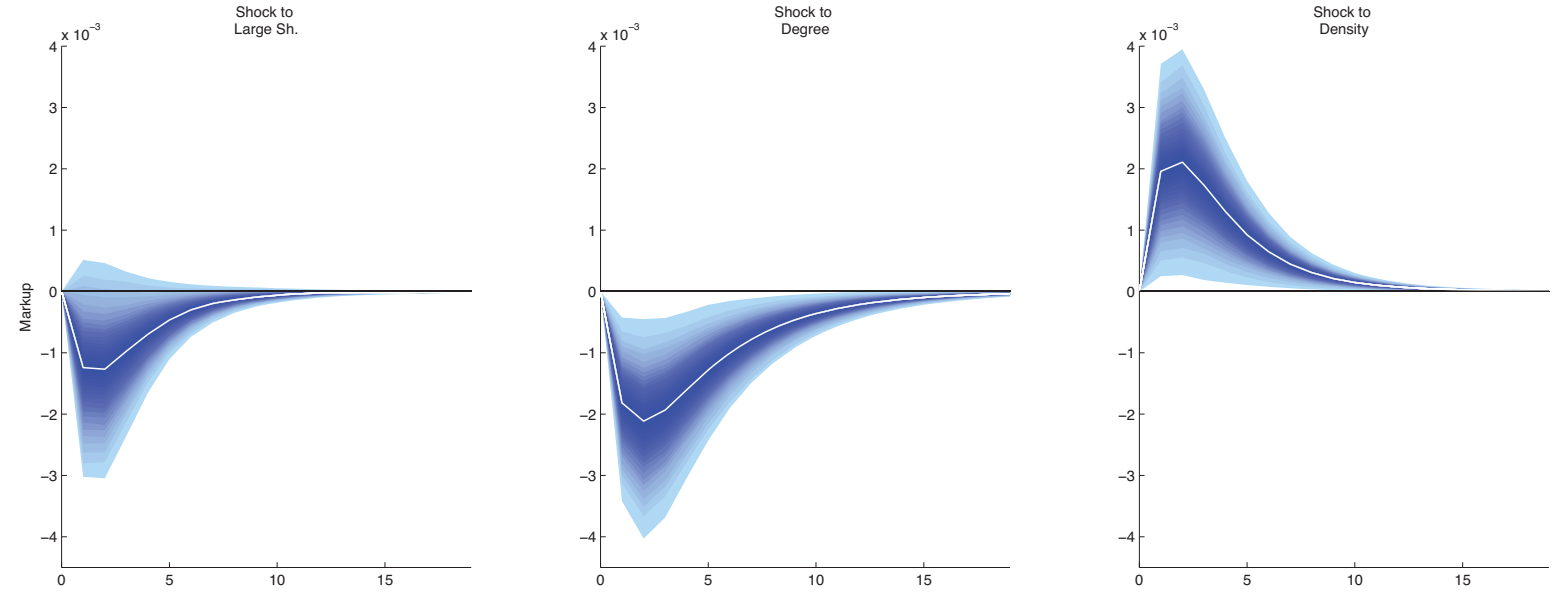

Figure 18

Response of the Average Industry Markup to Shocks to Ownership Structure Variables (including Industry Fixed Effects)

This figure shows the posterior density, in a Panel VAR model, of the response of average markups to shocks to the fraction of firms with large shareholders in the industry, the average overall degree of the firms in the industry, and the industry's shareholder subnetwork density. The endogenous variables in the VAR are average $\log$ assets, the Herfindahl index, average markups, the fraction of firms with a large shareholder, the average degree, and the density of the industry network. Quarterly dummies and industry fixed effects are treated as exogenous variables. In each figure, the $\mathrm{x}$ axis indicates number of quarters after shock. The graph shows bands from $5 \%$, up to $95 \%$, in intervals of $5 \%$. 

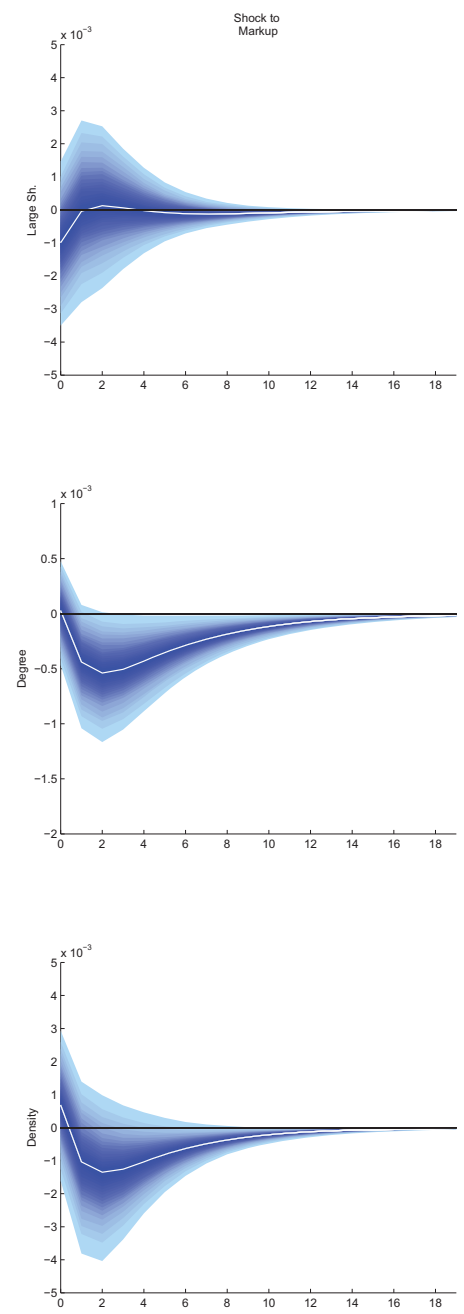

Figure 19

Response of Ownership Structure Variables to Shocks to Average Industry Markups (including Industry Fixed Effects)

This figure shows the posterior density, in a Panel VAR model, of the response of the fraction of firms with large shareholders in the industry, the average overall degree of the firms in the industry, and the industry's shareholder subnetwork density to shocks to average markups. The endogenous variables in the VAR are average log assets, the Herfindahl index, average markups, the fraction of firms with a large shareholder, the average degree, and the density of the industry network. Quarterly dummies and industry fixed effects are treated as exogenous variables. In each figure, the $\mathrm{x}$ axis indicates number of quarters after shock. The graph shows bands from $5 \%$, up to $95 \%$, in intervals of $5 \%$. 